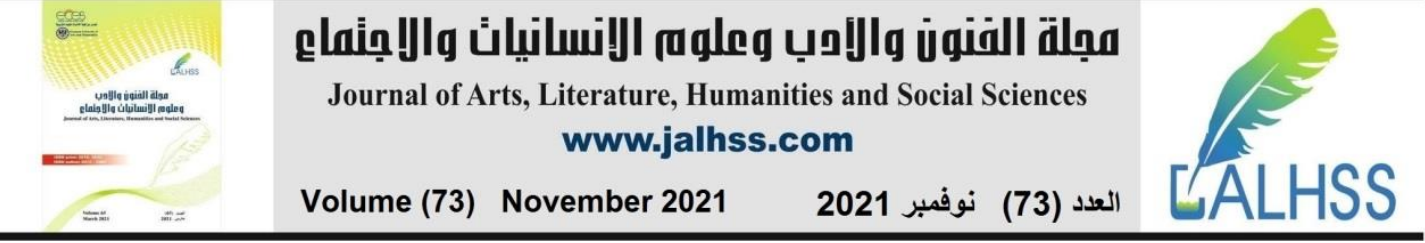

\title{
تمكين المرأة السعودية في ضوء روئية 2030
}

\section{د. عبيز عقيل محمد السرور}

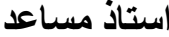

قسم العلوم السياسية ـ كلية الاقتصاد والإدارة ـ جامعة الملك عبد العزيز ـ المملكة العربية السعودية

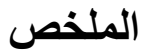

هدفت الدراسة إلى تبيان مؤشرات التمكين السياسي والاقتصادي للمرأة السعودية ضمن رؤية (2030) التي هدفت إلى زيادة مستويات التمكين للمر أة السعودية وسعت الدراسة للإجابة على التساؤل الرئيسي "ما هي نسب لهب تمكين المرأة السعودية اقتصاديا وسياسيا ؟ وما هي أهم المعوقات التي تقف أمام تمكين المرأة السعودية؟ ولمعالجة موضوع الدراسة تم الاستعانة بمنهج دراسة الحالة والمنهج الوصفي ويستفاد من المنهجان في هذه الدر اسة بتبيان مؤشر ات التمكين للمر أة السعودية الفعلي سواء في الجانب السياسي أو الاقتصادي. وقد بينت نتائج الدراسة زيادة نسبة المقاعد التي شغلتها المر أة السعودية في مجلس الثورى السعودي إلى نسبة ( 20\%) . وفيما يتعلق بمؤشرات التمكين الاقتصادي فقد ارتفع معدل الإلمام بالقراءة و الكتابة للإناث في المملكة

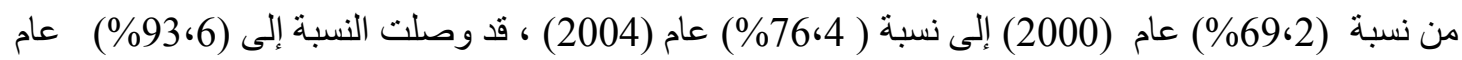
2013 ، ثم وصلت النسبة إلى (3،93\%) عام (2019) ـ كما ارتفعت نسبة مشار كتها الاقتصادية من (16.9\%) عام 2000 إلى نسبة (19،2\%) عام 2015. ثم ارتفعت النسبة إلى ( 24،3\% ) عام 2016، وهو ما يعكس بشكل أساسي زيادة مشاركة المر أة السعودية في القوى العاملة. كما ارتفع منوسط دخل المر أة السعودية مقارنة المانة بالرجل من نسبة (17\%) من دخل الرجال في عام (2000) ، إلى نسبة (21\%) عام (2002) ، ثم وصلت النسبة إلى (28\%) ثم عادت النسبة للانخفاض حتى وصلت إلى نسبة ( 23،7\% ) عام 2019 ـ. ورغم ضخامة سوق العمل السعودي، فما زالت تعاني من البطالة، المرتفعة، حيث ارتفعت من نسبة (9.5\%) تقريبا عام 2000 إلى نسبة (171\%) عام 2010 ، ووصلت النسبة إلى (22.9\%) عام 2019 . 


\begin{tabular}{|c|c|c|c|c|}
\hline DOI: 10.331 & LLHSS.73.2 & 1.596 & & $\begin{array}{l}\text { ISSN online: } 2414-3383 \\
\text { ISSN print: } 2616-3810\end{array}$ \\
\hline Cos & $\begin{array}{r}\text { QLingllg } \\
\text { Journal of A }\end{array}$ & $\begin{array}{l}\text { ts, Literature, Hur } \\
\text { www.jalhs }\end{array}$ & $\begin{array}{l}\text { es and Social Sciences } \\
\text { om }\end{array}$ & \\
\hline$=$ & Volume (73) & November 2021 & العدد (73) نوفمبر 2021 & \\
\hline
\end{tabular}

\title{
Empowering Saudi Women in Light of Vision 2030
}

\author{
Dr. Abeer Aqil Muhammad Al-Surour \\ Assistant Professor \\ Department of Political Science - College of Economics and Administration - King \\ Abdulaziz University - Kingdom of Saudi Arabia
}

\begin{abstract}
The study aimed to clarify indicators of political and economic empowerment of Saudi women within a vision (2030) Which aimed to increase the levels of empowerment of Saudi women. The study sought to answer the main question, "What is the percentage of Saudi women economically and politically empowered?" and What are the most important obstacles that stand in the way of empowering Saudi women? To deal with the subject of the study, the case study approach and the descriptive approach were used. The two approaches in this study are used to show the actual empowerment indicators for Saudi women, whether on the political or economic side. The results of the study indicated that the percentage of seats held by Saudi women in the Saudi Shura Council increased to $(20 \%)$. With regard to indicators of economic empowerment, the literacy rate for females in the Kingdom increased from $(69.2 \%)$ in $(2000)$ to $(76.4 \%)$ in $(2004)$, the percentage reached (93.6\%) in 2013, then the percentage reached (93.3\%) in (2019). The percentage of their economic participation increased from (16.9\%) in 2000 to (19.2\%) in 2015. Then the percentage increased to (24.3\%) in 2016. This mainly reflects the increased participation of Saudi women in the workforce. The average income of Saudi women compared to men increased from (17\%) of men's income in (2000), to (21\%) in (2002). Then the percentage reached $(28 \%)$ then the percentage decreased until it reached $(23.7 \%)$ in 2019. Despite the enormity of the Saudi labor market, it still suffers from high unemployment, as it increased from approximately $(9.5 \%)$ in 2000 to $(17.1 \%)$ in 2010 , and reached $(22.9 \%)$ in 2019.
\end{abstract}

Keywords: empowering women, Saudi women, vision 2030. 


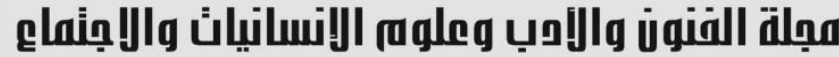

Journal of Arts, Literature, Humanities and Social Sciences www.jalhss.com

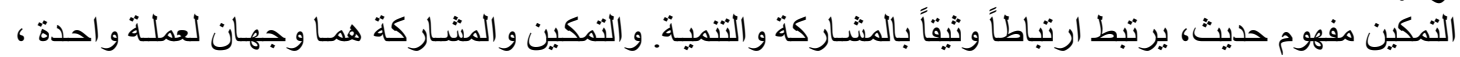

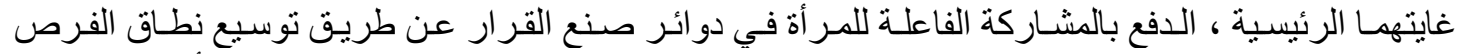

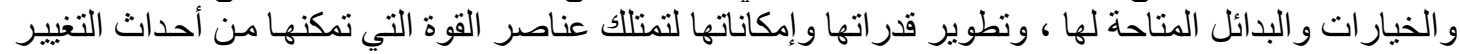

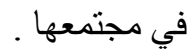

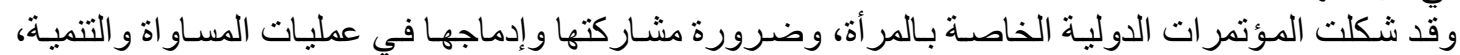

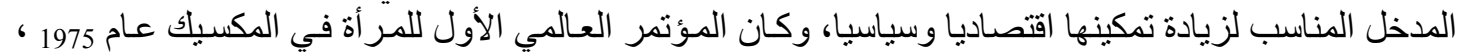

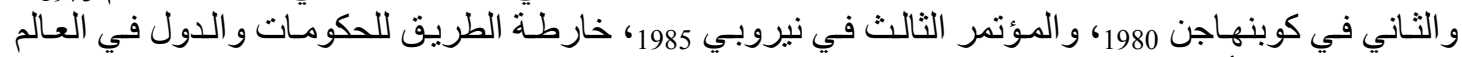

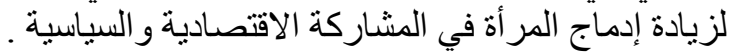

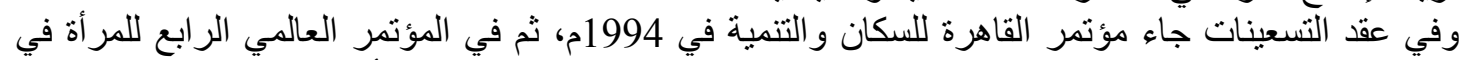

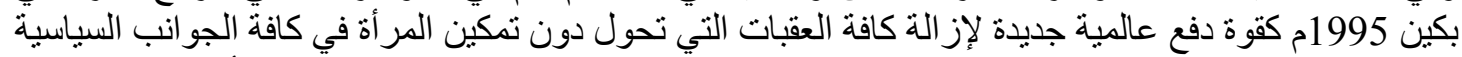

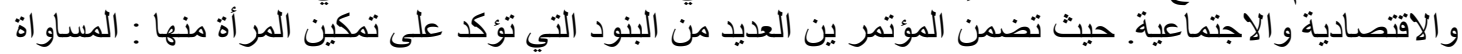

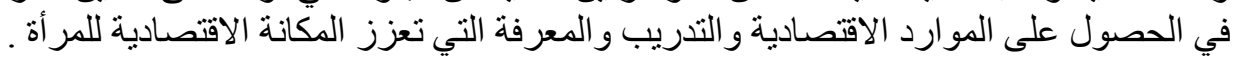

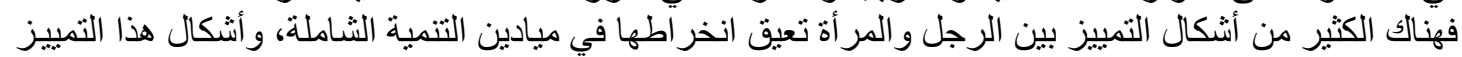

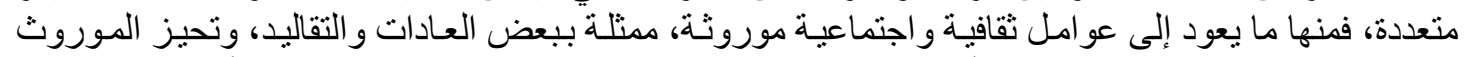

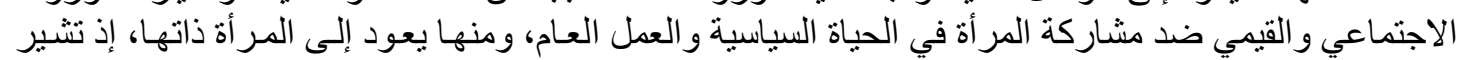

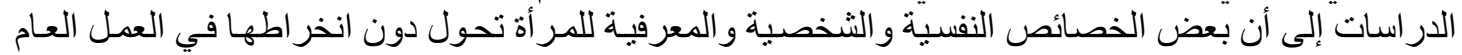

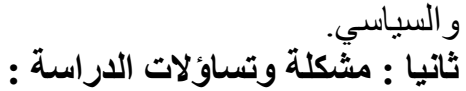

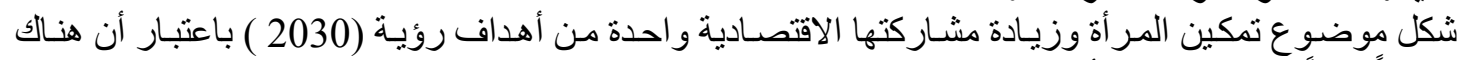

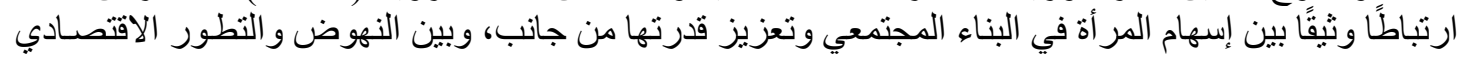

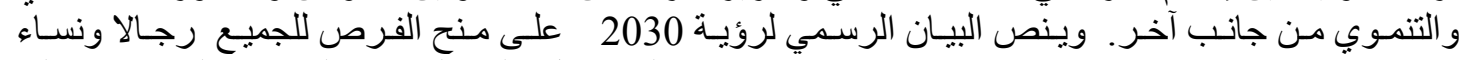

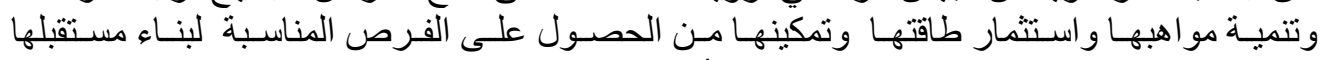

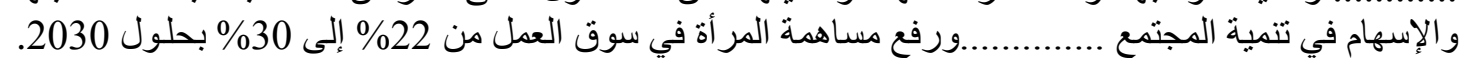

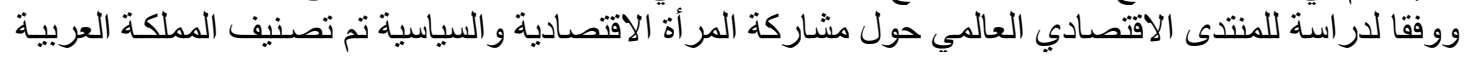

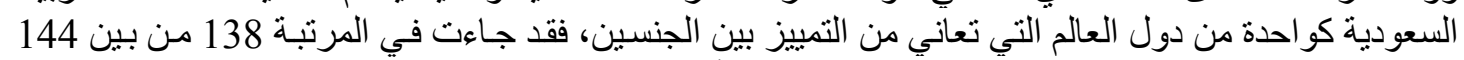

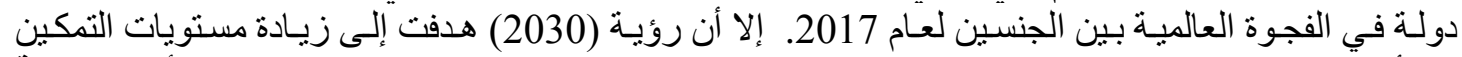

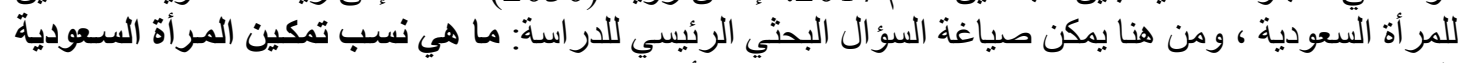

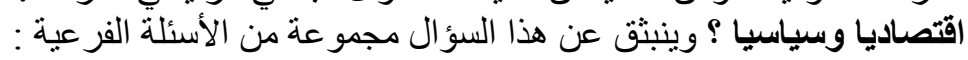

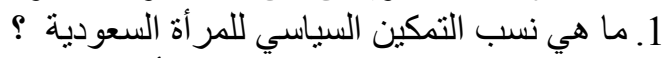

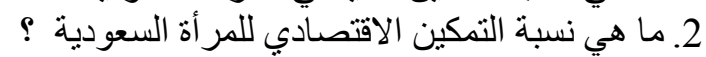

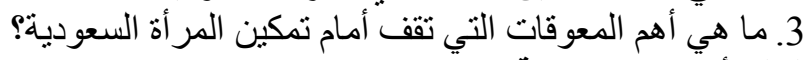

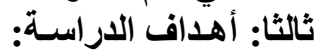

إن تمكين المر أة هدف بحد ذاته وتكمن أهمية الدراسة في أهمية دور المر أة التنموي، إذ إنه مع زيادة إنهادة تمكينها

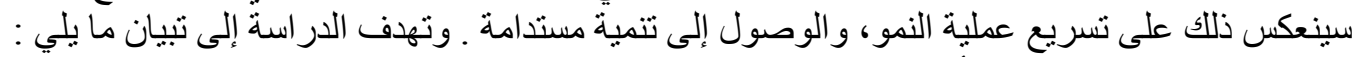

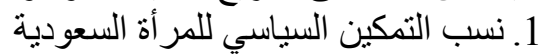

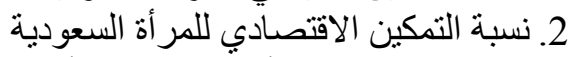

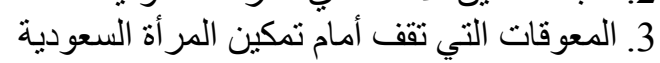

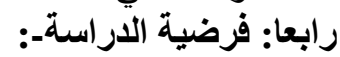

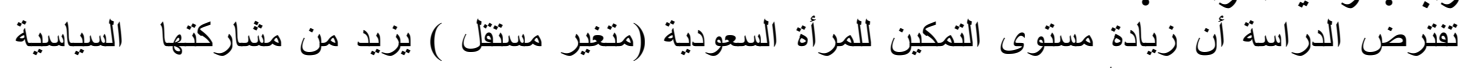
و الاقتصادية ( متغير مستقل ) ) 


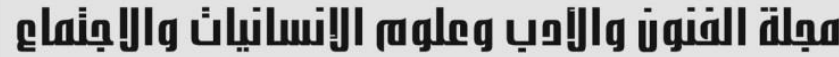

Journal of Arts, Literature, Humanities and Social Sciences www.jalhss.com الحدود الزمانية : تمتد الدر اسة خلادل الفترة ( 2010-2020 ) و هي فترة زمنية كافية لمعرفة الاتجاهات العامة

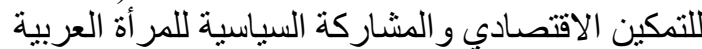

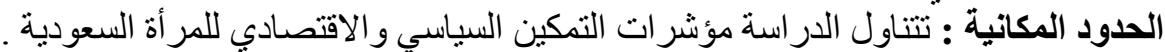

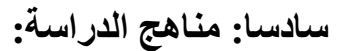
لمعالجة موضو مناوع الدر اسة سيتم الاستعانة بالمناهج التالية:

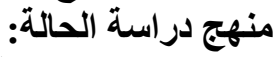
تميز منهج در استة حالة بكونه يهدف إلى التعرف على التى وضعية واحدة معينة ، وبطريقة تفصيلية دقيقة .

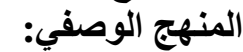
يمتاز المنهج الوصفي بأنها:ه منهج، يصف الظاهرة المدروسة وصفا دقيقا ويعبّر عنها كيفيا، وكميا، من خلال أرقام وجداول توضح مقدار التغير في الظاهرة ـ ويستفاد من المنهج في هذه الدراسة بنبيان مؤشرات التهات التمكين للمر أة السعودية الفعلي سواء في الجانب السياسي أو الاقتصادي.

ثامنا: الار اسات السابقة:

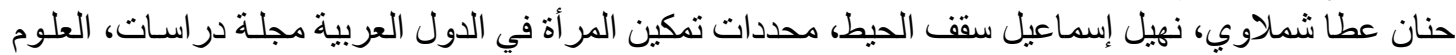

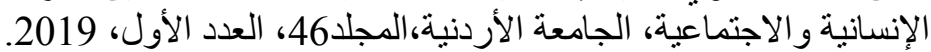

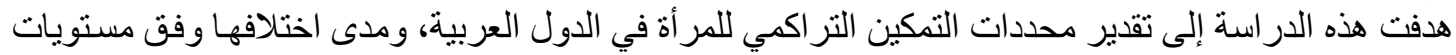

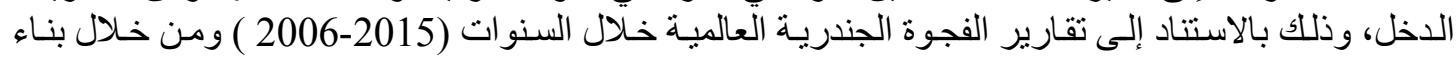

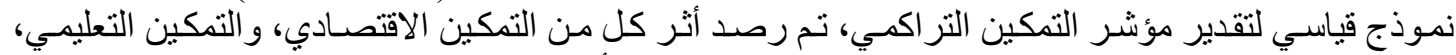

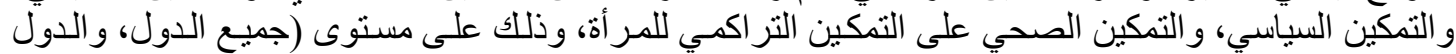

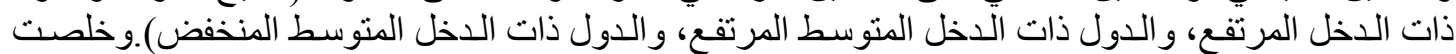

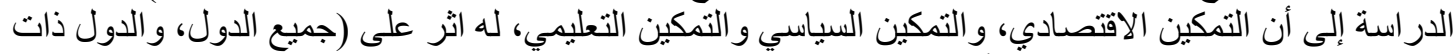

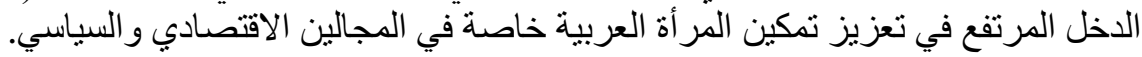

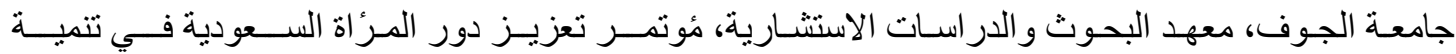

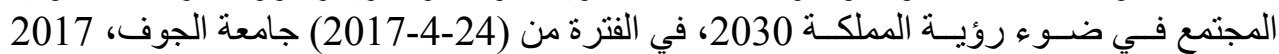

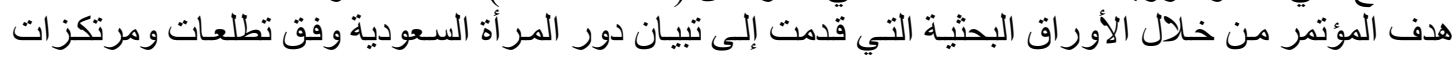

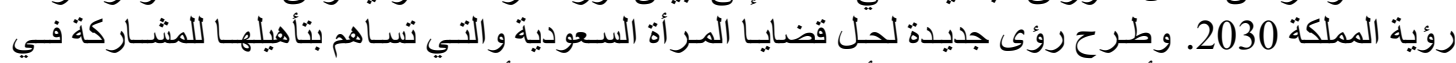

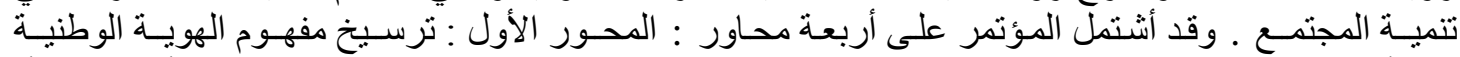

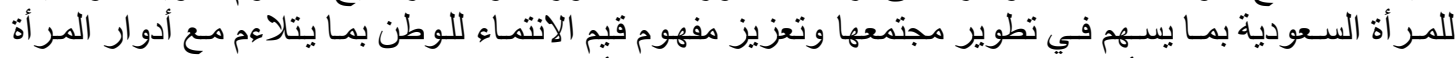

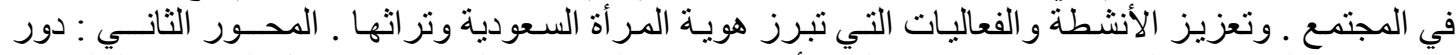

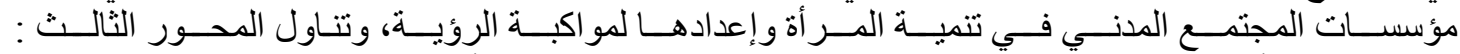

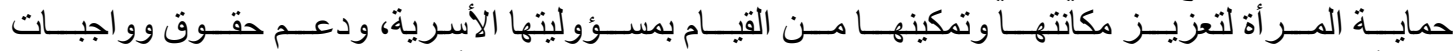

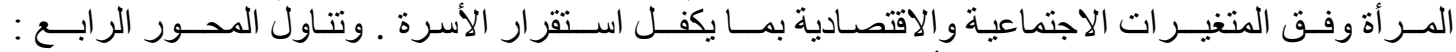

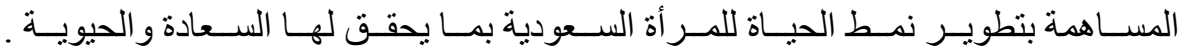

هند عقيل الميزر ، المر أة السعودية من التهميش إلى التمكين في التعليم و العمل المجلة العربية للار اسات الأمنية ـ

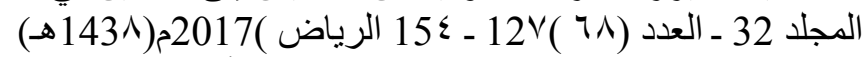

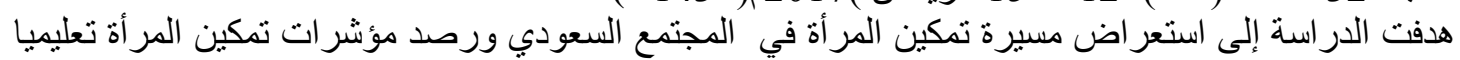

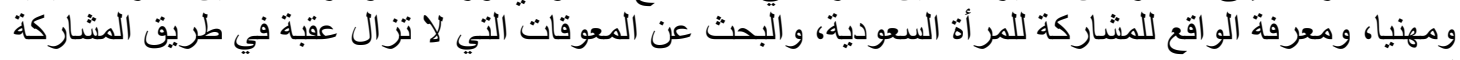




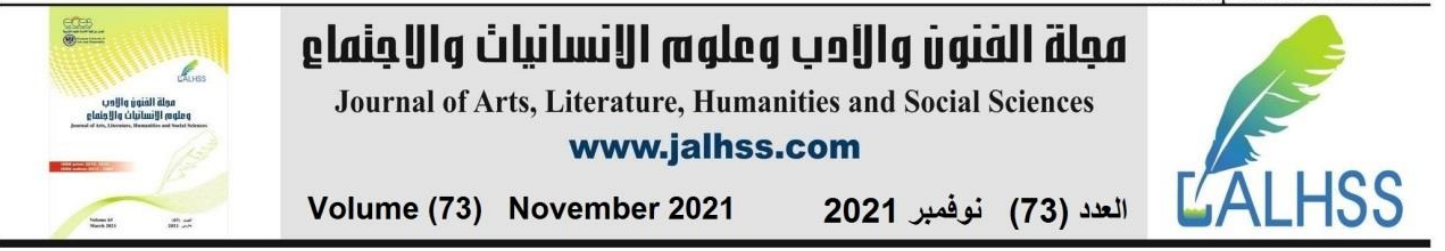

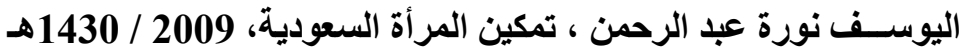

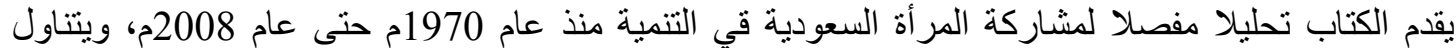

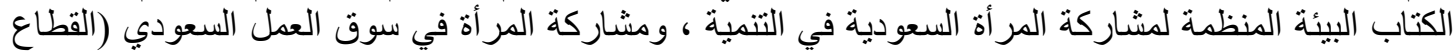

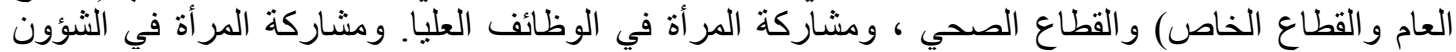

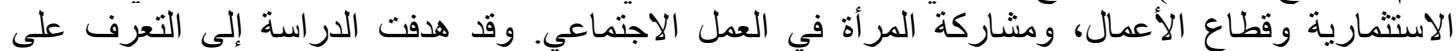

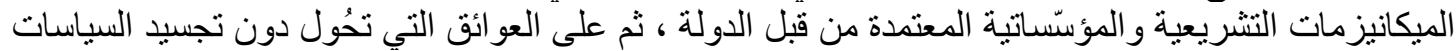

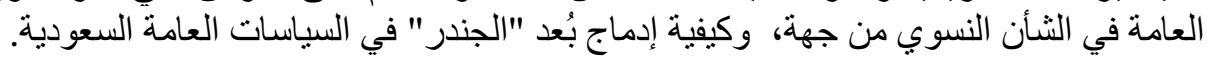

\section{الفصل الأول: التمكين: النشأة، المفهوم}

المبحث الأول: التمكين

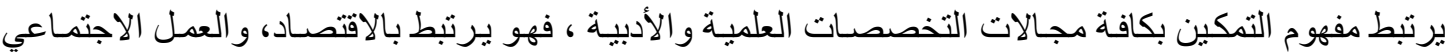

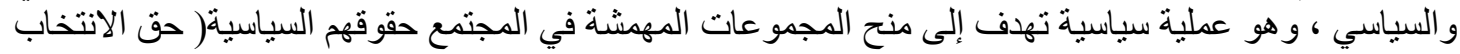

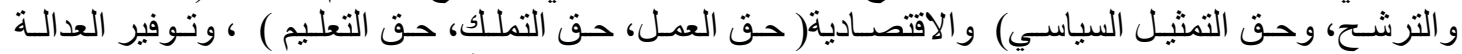
الاجتماعية لهم. كما امتد مفهوم التمكين كمصطلح للتعبير عن عملية فردية يأخذ فيها الفرد المسؤولية ولئ السيطرة

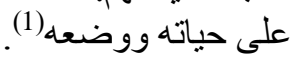
المطلب الأول: تعريف المفهوم

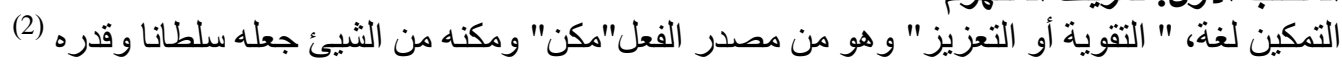
و التمكين اصطلاحا هو " زيادة قدرة النساء على اتخاذ خيارات إستر اتيجية متعلقة بحياتهم في إطار معين بعدما

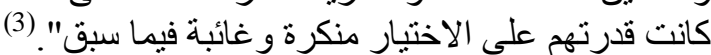

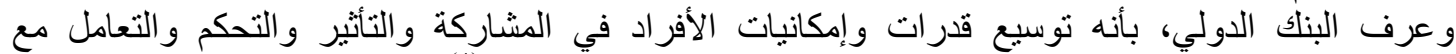

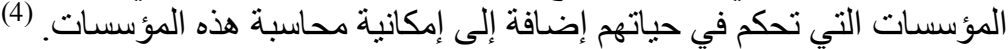

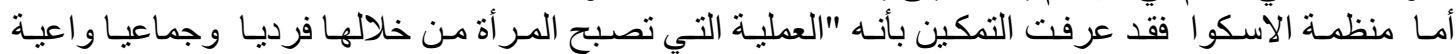

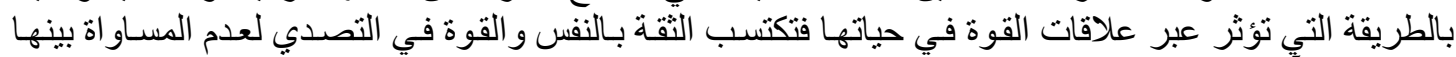

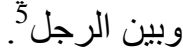

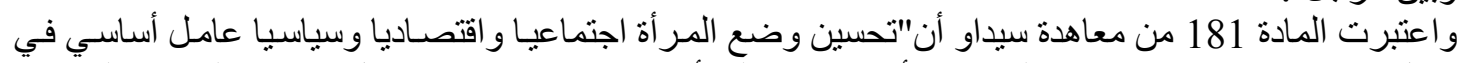

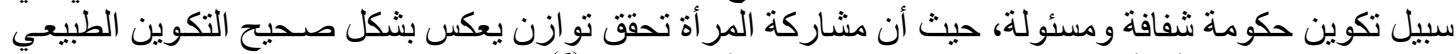

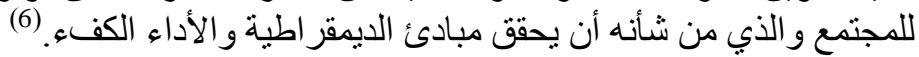

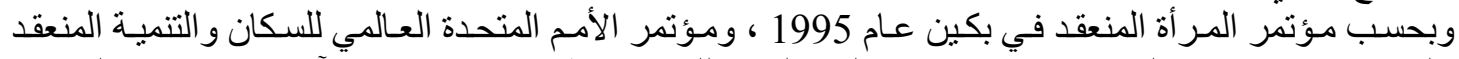

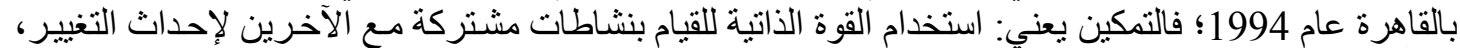

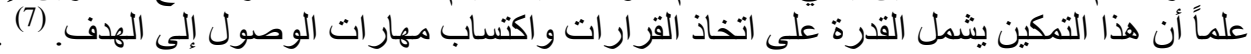

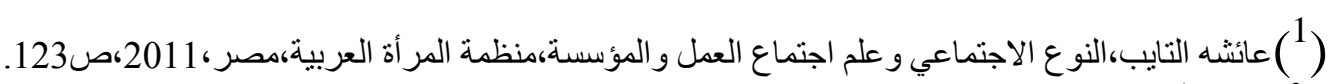

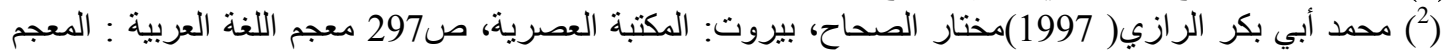

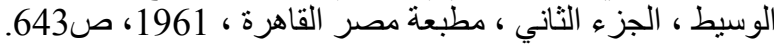

( $\left.{ }^{3}\right)$ Barara Rowland- Sedar, Peregrine Scwartz-shea, "Empowering Women: Self Autonomy and Responsibility", The Western Political Quarterly, Vol. 44, No.3, Sep., 1991, p.p.605-624.

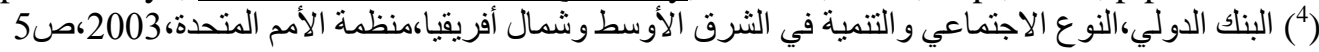

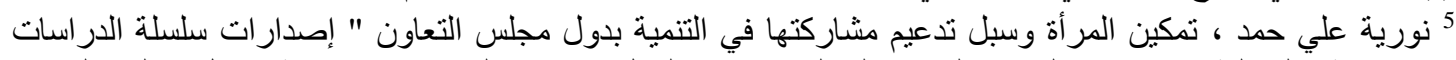

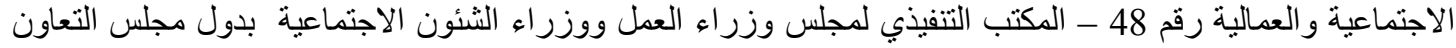

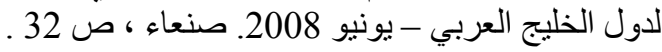

$\left({ }^{6}\right)$ The United Nations Fourth World Conference on Women: Platform for Action, (China:1995): (http://www.un.org/womenwatch/daw/beijing/platform/decision.htm) 


\section{همالة الفنون والأوب وماوه الإنسانيائ والإيiهاع}

Journal of Arts, Literature, Humanities and Social Sciences www.jalhss.com

Volume (73) November 2021

العدد (73) نوفمبر 2021

و اقترح تقريـر التنميـة الإنسـانية العربيـة الأول في 2002 استخدام مصطلح "نهوض المـر أن" بـدلا من مصطيلح

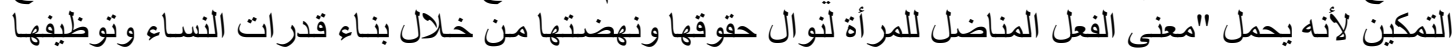
بفعالية في سباق مجتمعي ". ويرى الكثير من الباحثين في هذا السياق أن تمكين المر أة يتطلب تحو لاً منتظماً في كافة مؤسسات الدولة و لا سيما

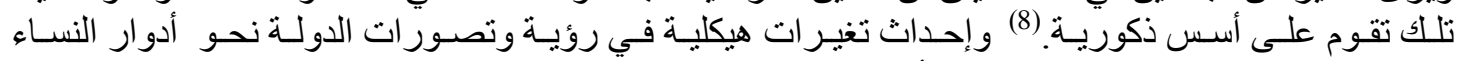

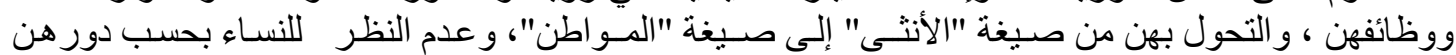

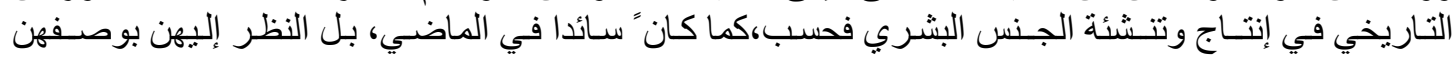

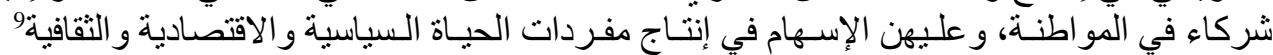

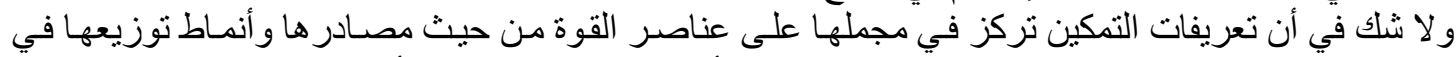
المجتمع، وكونه عملية ديناميكية، تسعى للقضاء على كلى أشكال على عدم المساو اة بين أفر اد المجتمع. ويتجلى التمكين في العوامل التالية 10 :

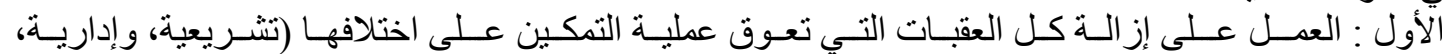
واجتماعية... إلخ) التي تعرقل مشاركة النساء.

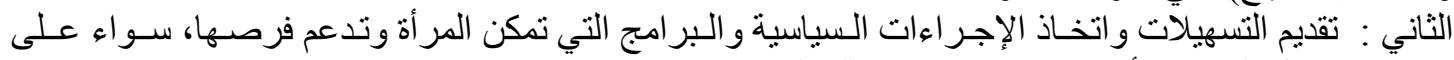

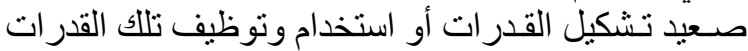
وهو ما يمكن تحقيقه عبر المحاور الآتية: الثالث: تتمية قدر ات ومعارف فئه ومهار ات الفئات المهمشة 11 و القضاء على مظاهر الإقصاء و التهميش على التى النحو

الذي يكفل للمر أة الاندماج في المجتمع بمشاركة فاعلة وفرص متكافئة اقتصاديا و اجتماعيا وسياسيا. (12)

المطلب الثاني : التمكين الاقتصادي والسياسي التماني

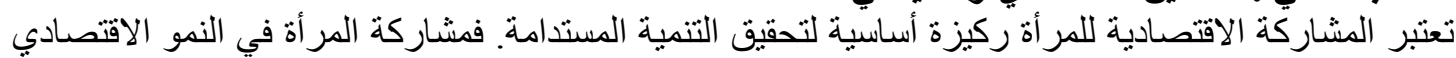

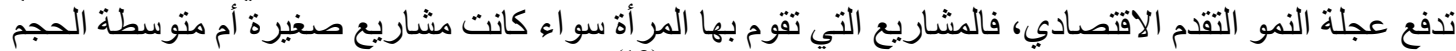

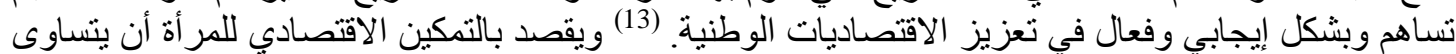

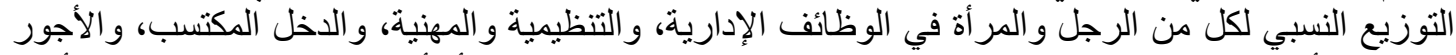

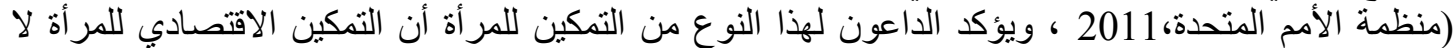

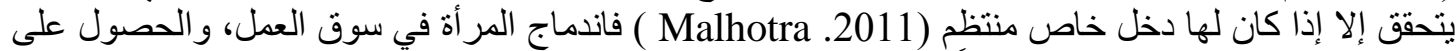

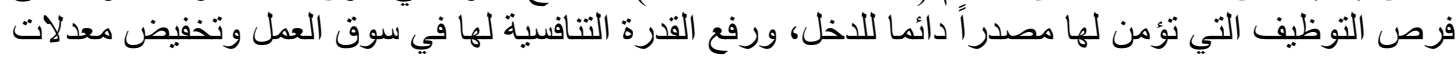

( $^{7}$ Gita Sen and Batilwala Sirilatha, "Empowering Women for Reproductive Rights", Women's Empowerment and Demographic Process, Moving Beyond Cairo, New York: Oxford University Press, 2000, p. 18

(") ريتو شارما، مدخل إلى المدافعة ، ترجمة المعهد الديمقر اطي الوطني للشئون الدولية، لبنان، الوكالة الأمريكية للتنمية

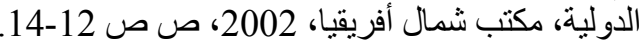

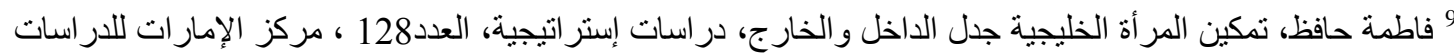

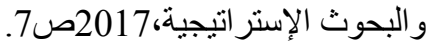

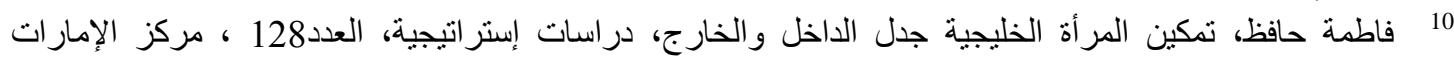

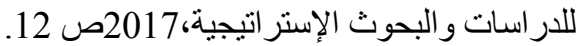

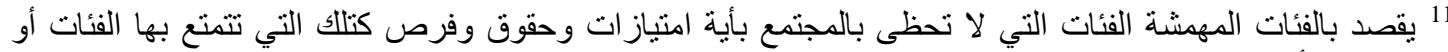

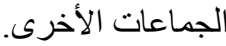
(2) أماني مسعود، نظريات التمكين و علاقته بالتنمية في الوطن العربي، في تجديد القيادة والتنمية في الوطن العربي،

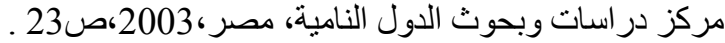

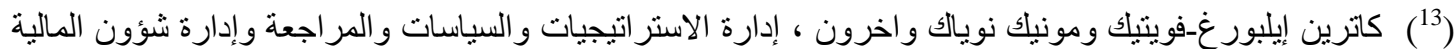

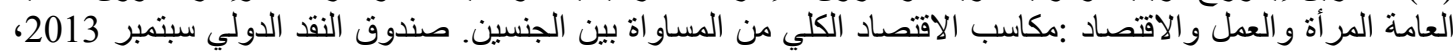




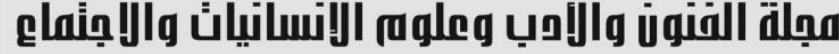

Journal of Arts, Literature, Humanities and Social Sciences www.jalhss.com

البطالة بين الفتبات. يجعلها تحصل على استقلالها الاقتصادي عن الرجل، وتصبح قرار اتها المادية بيدها،

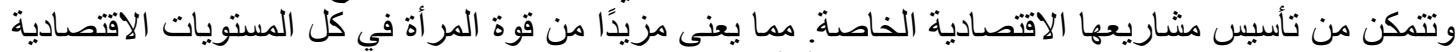

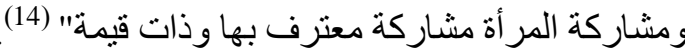
مؤشرات تمكين المرأة السعودية

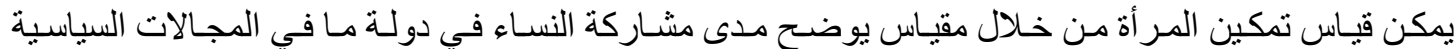

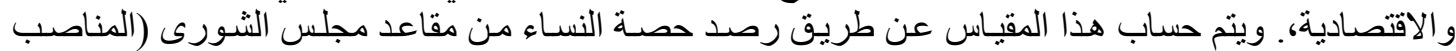

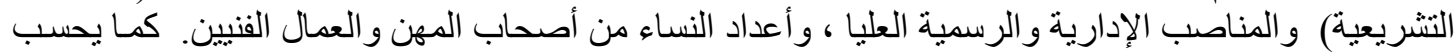

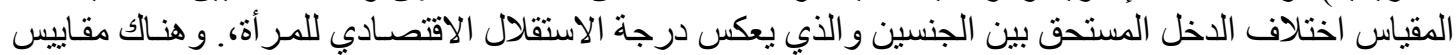

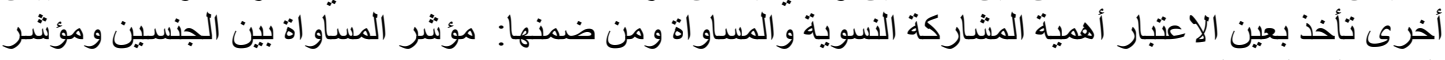

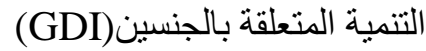
المطلب الأول: المؤشرات السياسية

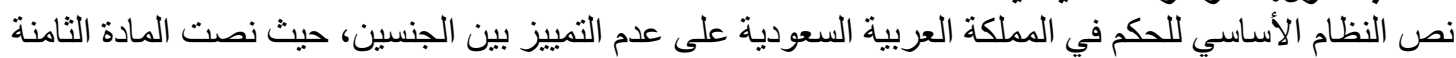

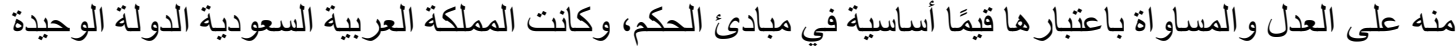

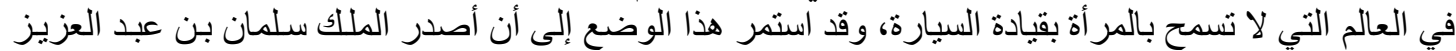

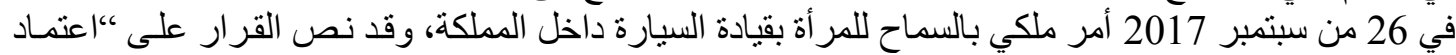

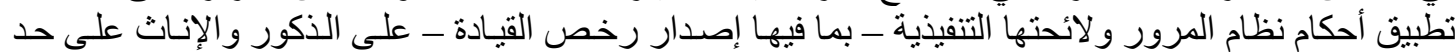

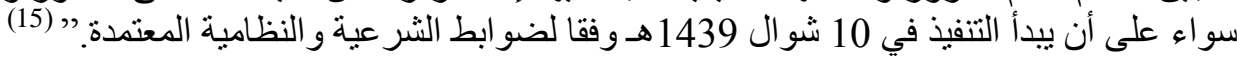

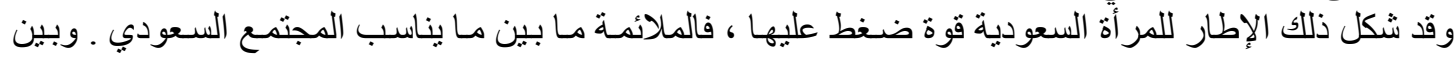

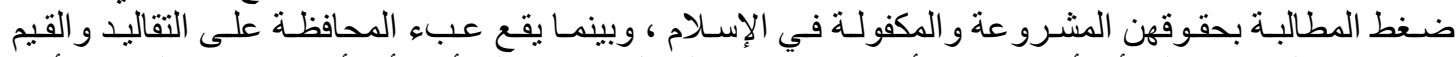

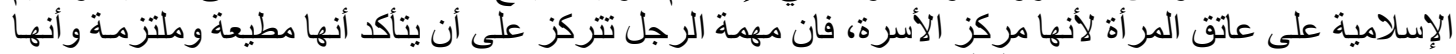

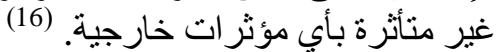

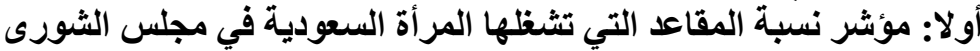

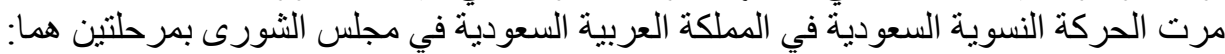

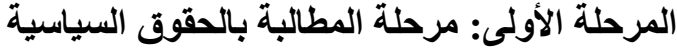

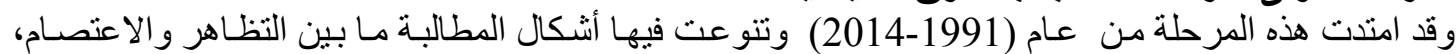

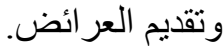
من المفارقات أنه بينما تم حرمان جموع النساء السعوديات مـن حق ممارسة' المشاركة في الانتخابـات البلديـة،

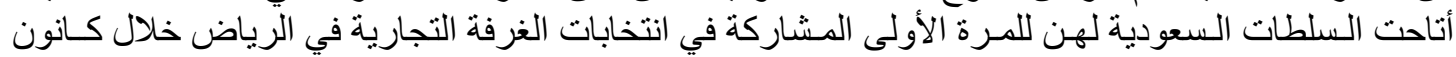

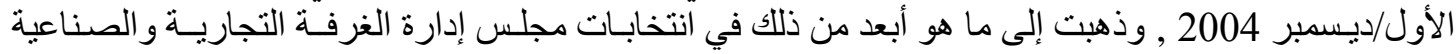

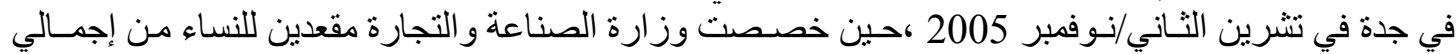

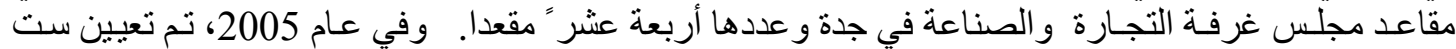

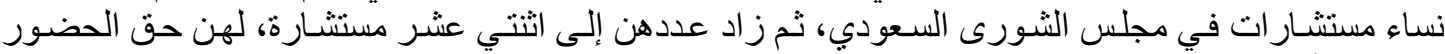

و إبداء الر أي من دون التصويت. 17

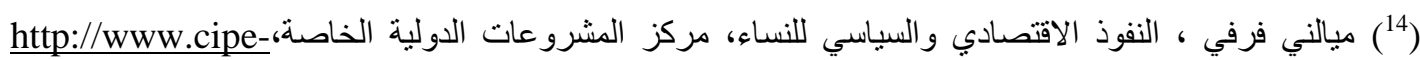
و واشنطن arabia.org/files/pdf/Feature_Service/Political_And\%20Economic_Power_of_Women.pd5 صنطن

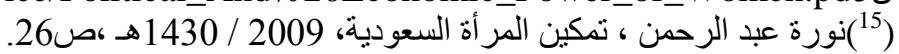

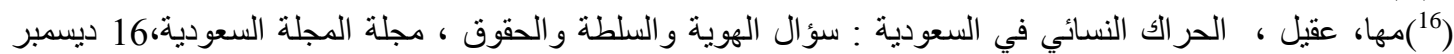

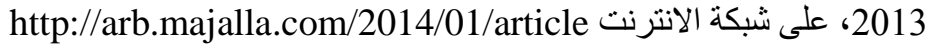
17 أوراق كارنيجي، المتاهة السعودية: تقويم الانفتاح السياسي الحالي،سلسلة الثرق الأوسط،رقم 66، ابريل- 


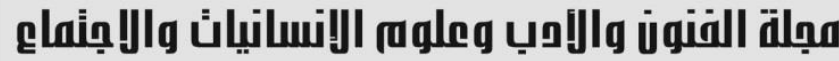

Journal of Arts, Literature, Humanities and Social Sciences www.jalhss.com

Volume (73) November 2021

العدد (73) نوفمبر 2021

\section{ALLHSS}

المرحلة الثانية: مرحلة دخول المرأة السعودية مجلس الثورى السعودي الثودي

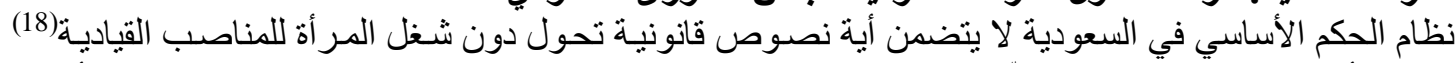

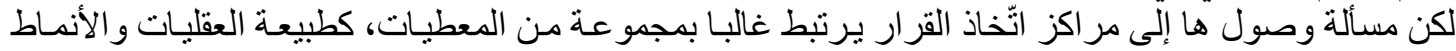

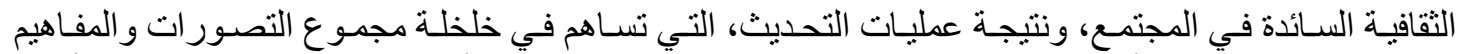

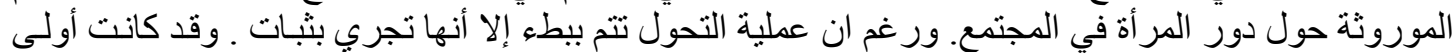

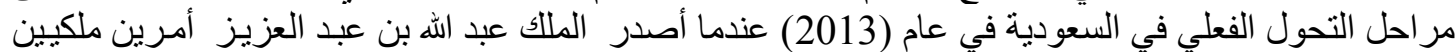

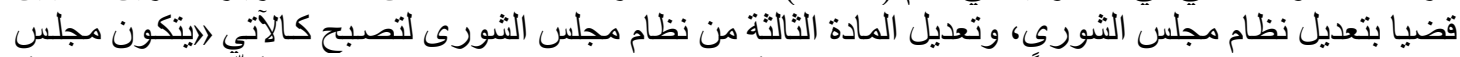

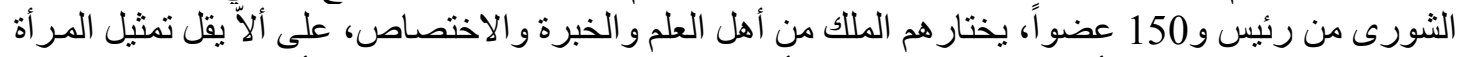

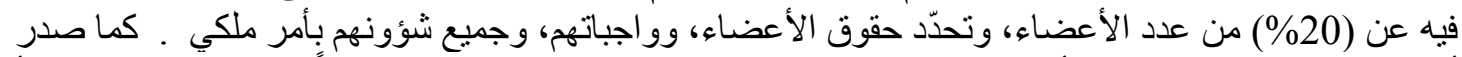

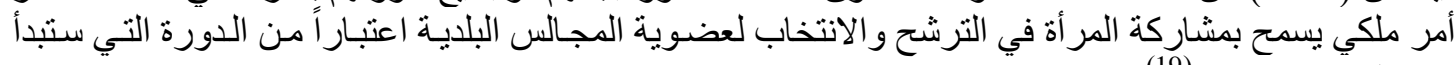

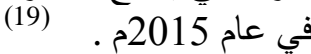

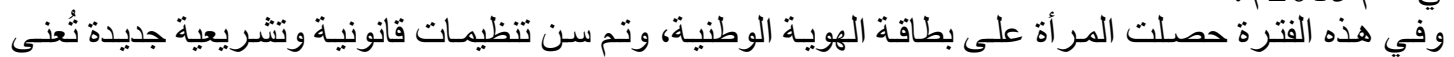

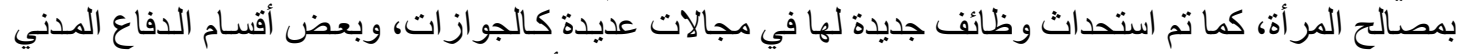

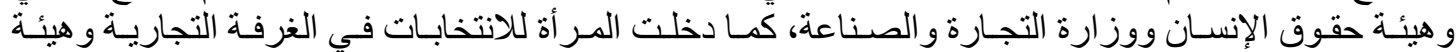

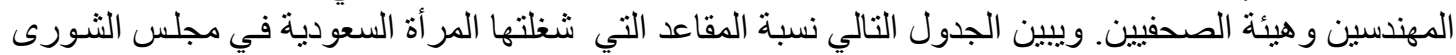

السعودي.

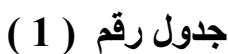

نسبة المقاعد التي شغتها المرأة السعودية في مجلس الثورى

\begin{tabular}{|c|c|c|c|}
\hline السنو ات & 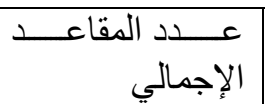 & عدد مقاعد النساء & النسبة \\
\hline 2015 & 150 & 30 & $20 \%$ \\
\hline 2019 & 150 & 30 & $20 \%$ \\
\hline \multicolumn{4}{|c|}{ المر اكز القيادية للمر أة السعودية } \\
\hline العدد & مسمى الوظيفة & العدد & مسمى الوظيفة \\
\hline 15 & عبيةة & 1 & نائب وزير \\
\hline 13 & عضوة في حقوق الإنسان & 3 & وكبل وزارة \\
\hline 2 & سفيره & 1 & مدير جامعة \\
\hline
\end{tabular}

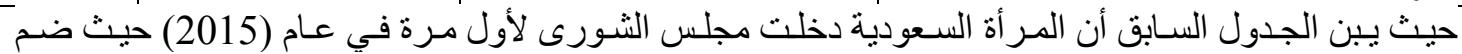

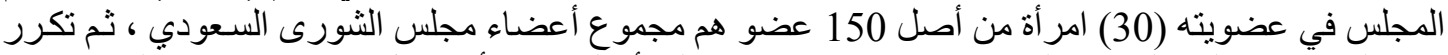

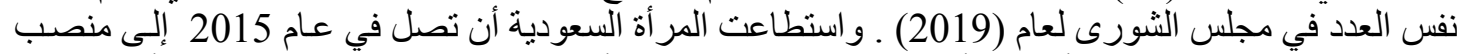

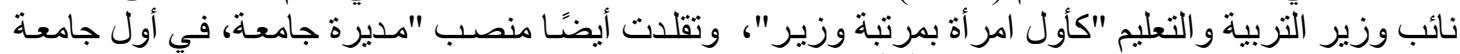

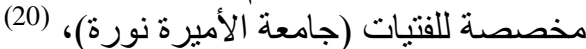

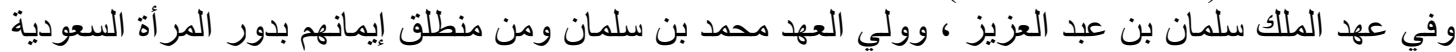

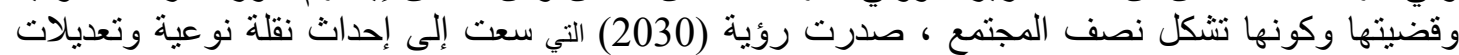

(18) الجربوع، أيوب ، و المحيسن خالد ، المركز القانوني للمر أة في المملكة العربية السعودية، دون دار نشر. (2010)ص

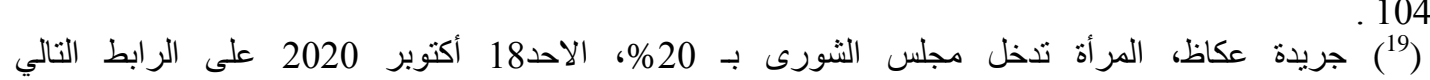
https://www.okaz.com.sa/news/local/2045145

(20) خضر ، عبد العزيز. السعودية: سيرة دولة ومجتمع، قراهة في تجربة ثلث قرن من التحولات الفكرية والسياسية

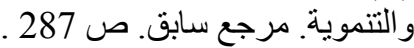




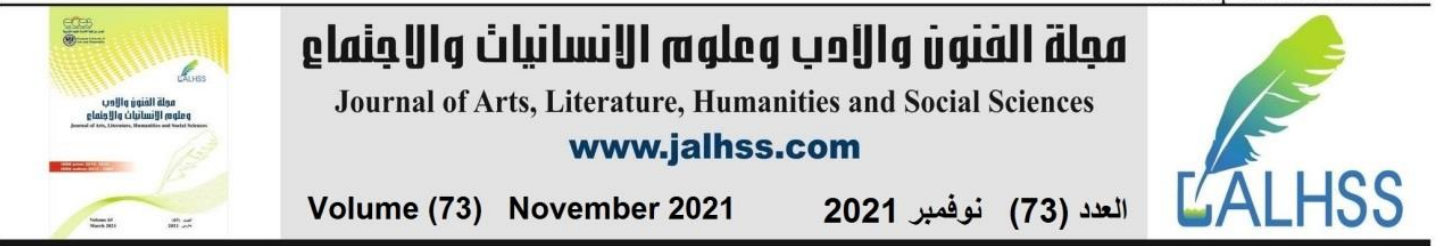

جوهرية في القوانين المتعلقة بالمرأة السعودية وحقوقها ، حيث أصبحت شريكاً مهمًا في العديد من الهيئات

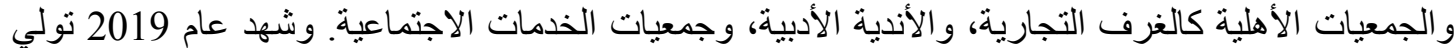

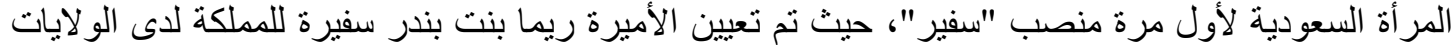

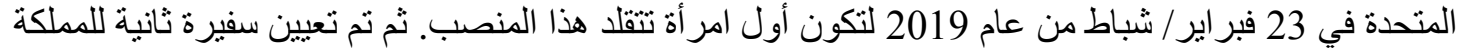

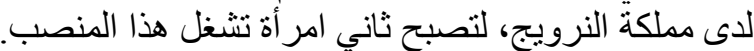

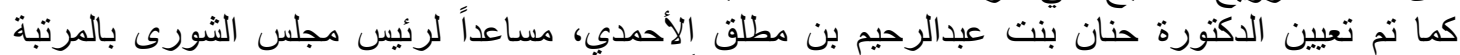

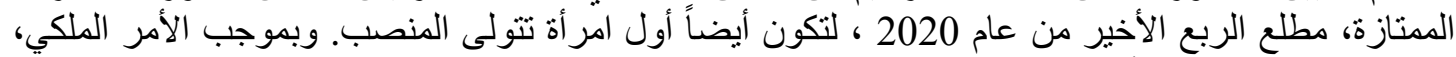

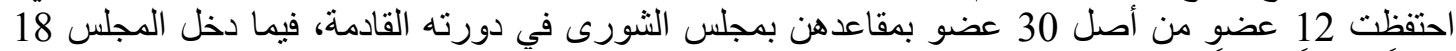

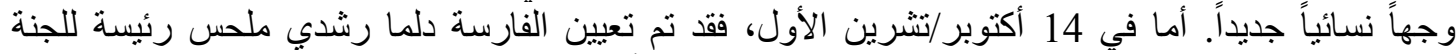

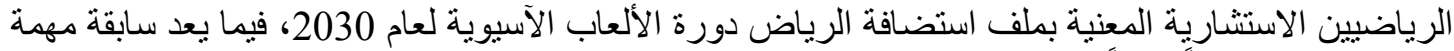

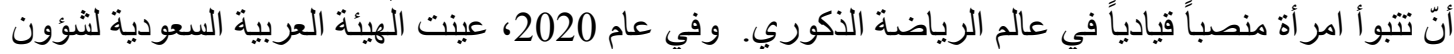

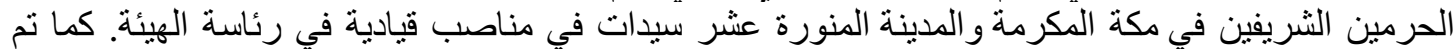

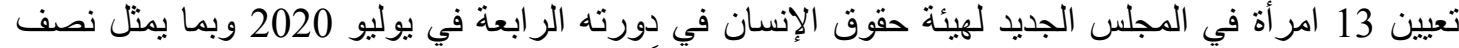

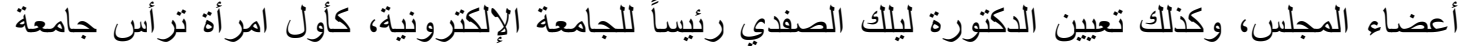

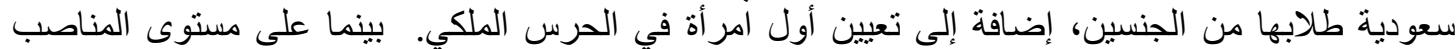

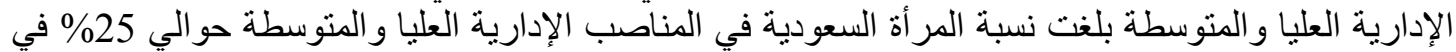
القطاع الخاص، و3.29\% في القطاع القاعة الحكومي.

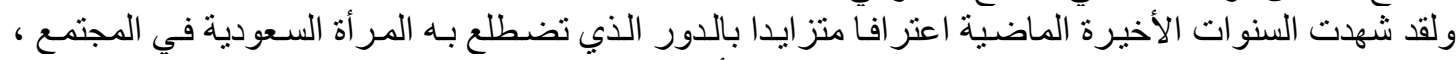

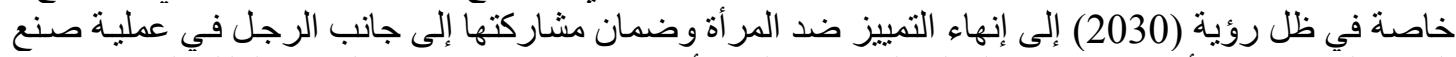

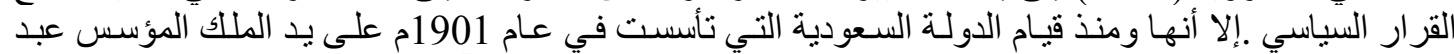

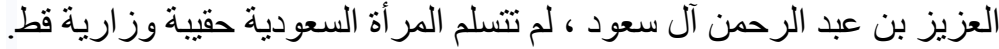
نسبة مشاركة المر أة السعودية في المبد المجالس المحلية

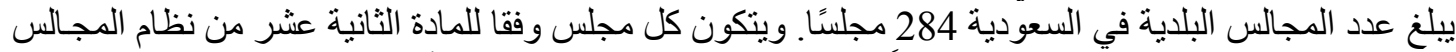

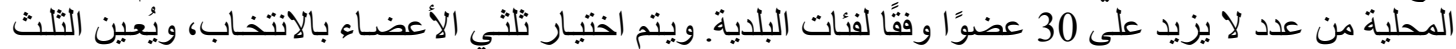

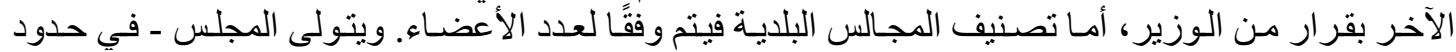

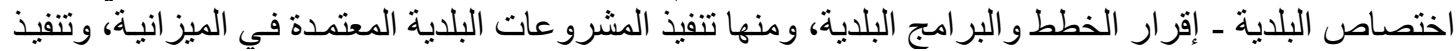

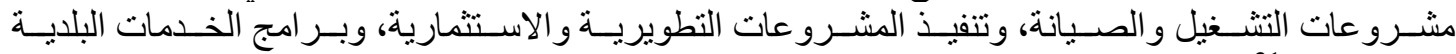

ومشرو عاتها.

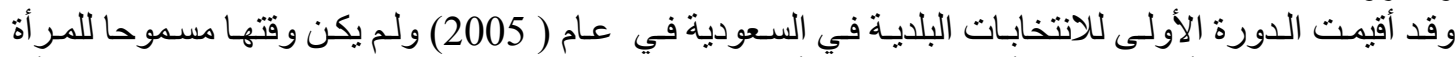

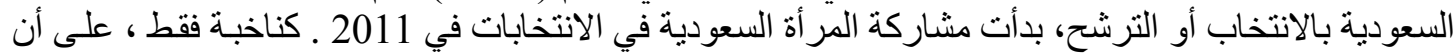

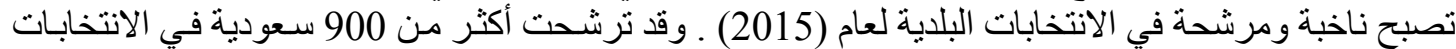

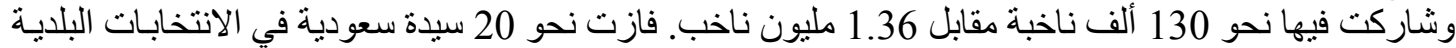
عام 2015 


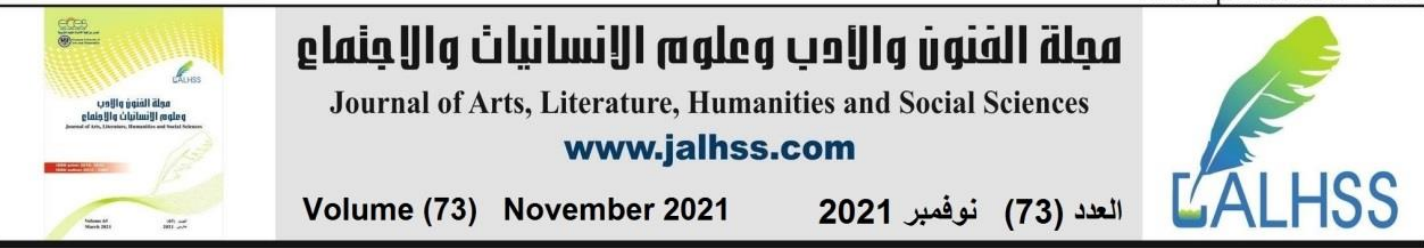

\begin{tabular}{|c|c|c|c|c|c|c|c|}
\hline \multicolumn{8}{|c|}{ جدول (1) } \\
\hline السنو ات & المجـالس & الإجمال & المترشحين & المترشــد النســــــاء & الفائز ات عـــد & المعينات & النسبة \\
\hline 2015 & 284 & 3159 & 7896 & 979 & 20 & 17 & $1 \%$ \\
\hline 2018 & 284 & 3156 & $86 \%$ & $14 \%$ & 20 & 18 & $1 \%$ \\
\hline
\end{tabular}

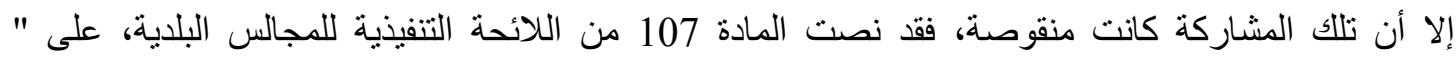

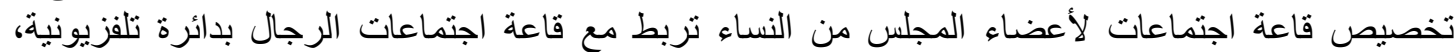

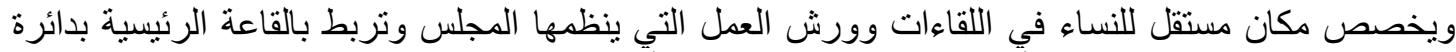

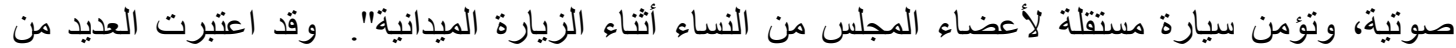

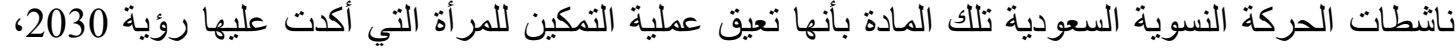
وفي عام (2019 ) تم إلغاء المادة . لمانية

المظلب الثاني: المشاركة الاقتصادية للمرأة السعودية المادية

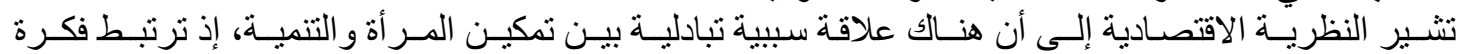

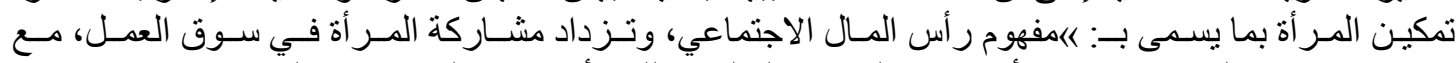

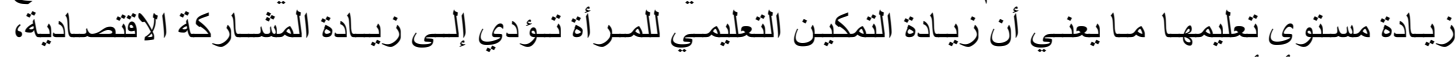

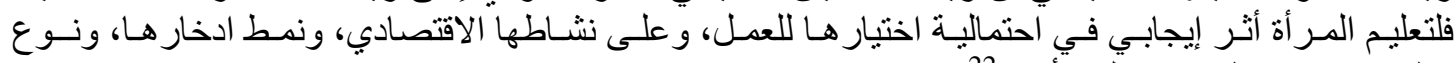
وظيفتهـا، ونمـــ اســتهلآك الأسرة:22.

\section{مؤشرات التمكين الاقتصادية}

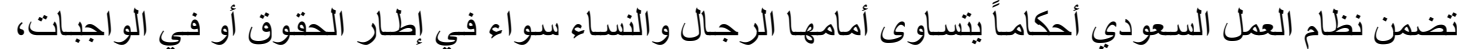

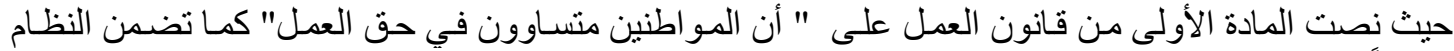

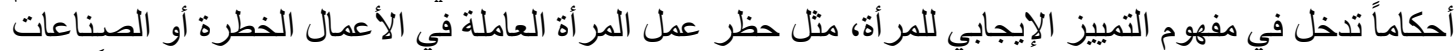

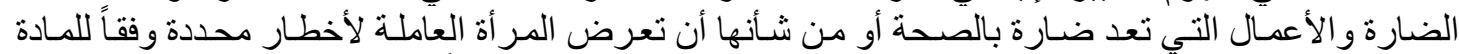

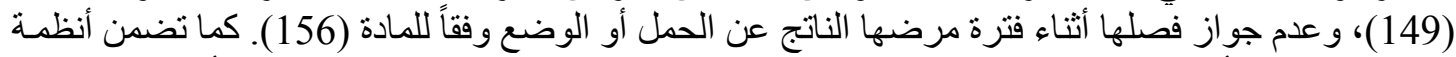

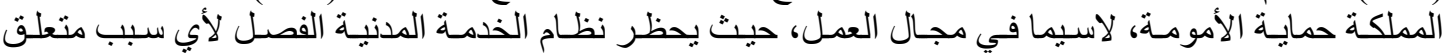

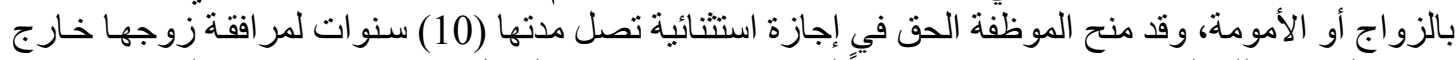

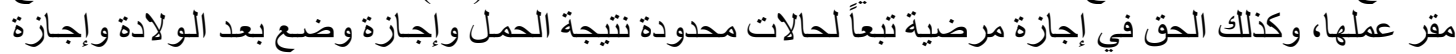

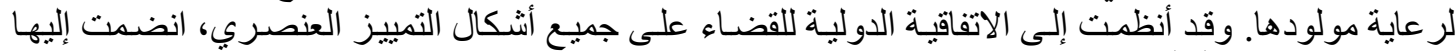

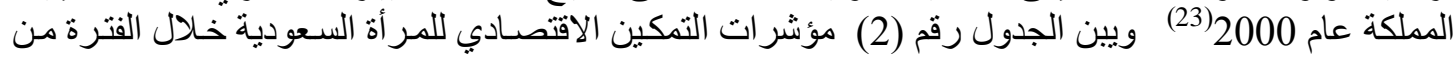
عام (2000-2000 )

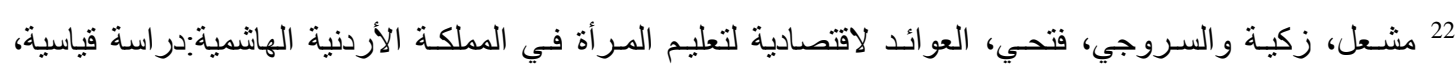

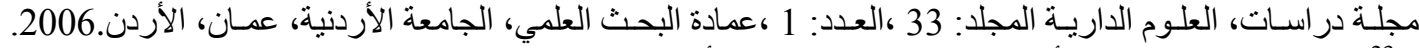

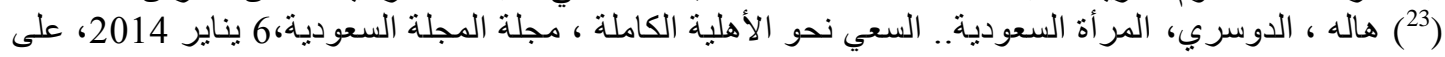

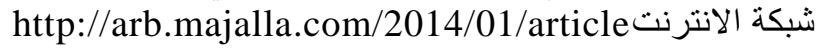




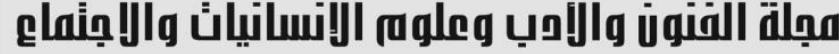

Journal of Arts, Literature, Humanities and Social Sciences www.jalhss.com

Volume (73) November 2021

العدد (73) نوفمبر 2021

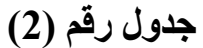

مؤشرات تمكين المرأة السعودية اقتصاديا (2000-2020)

\begin{tabular}{|c|c|c|c|c|c|}
\hline 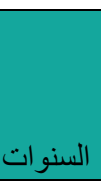 & المبة المر أة في كافة الإدارية & 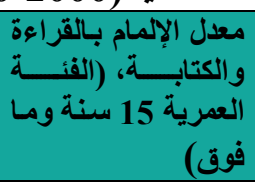 & للإنـاث مُشر معدلات البطالـة & 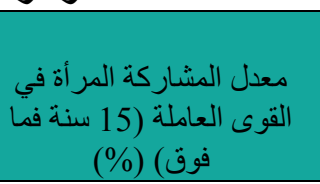 & نسبة العمالة إلى عدد \\
\hline 2000 & & 69.2 & 9.5 & 16.9 & $\begin{array}{r}13.9 \\
\end{array}$ \\
\hline 2001 & & & 9.3 & 16.7 & 13.7 \\
\hline 2002 & & & 11.7 & 16.7 & 13.7 \\
\hline 2003 & & & 12.6 & 17.3 & 14.0 \\
\hline 2004 & & 76.3 & 12.3 & 17.9 & 14.2 \\
\hline 2005 & & & 17.3 & 18.6 & 14.6 \\
\hline 2006 & 0.9 & & 15.3 & 19.2 & 15.0 \\
\hline 2007 & & & 14.5 & 18.7 & 14.6 \\
\hline 2008 & & & 14.2 & 18.4 & 14.4 \\
\hline 2009 & & & 16.2 & 18.4 & 14.1 \\
\hline 2010 & & & 17.1 & 19.2 & 14.9 \\
\hline 2011 & & & 18.8 & 20.6 & 15.4 \\
\hline 2012 & & & 21.2 & 21.3 & 15.8 \\
\hline 2013 & 6.8 & 91.3 & 21.1 & 21.4 & 15.3 \\
\hline 2014 & & & 21.7 & 23.3 & 15.5 \\
\hline 2015 & 0.7 & 91.7 & 21.1 & 21.8 & 16.2 \\
\hline 2016 & & 92.5 & 21.1 & 24.3 & 16.7 \\
\hline 2017 & & 93.0 & 20.3 & 23.7 & 16.3 \\
\hline 2018 & & 93.2 & 22.4 & 23.1 & 15.9 \\
\hline 2019 & & 93.3 & 22.9 & 23.3 & 15.8 \\
\hline
\end{tabular}

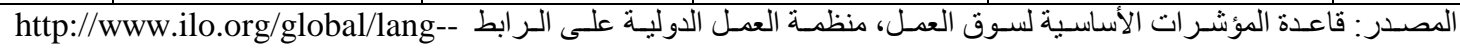
en/index.htm

http://www.arabdevelopmentportal.com/dv/datae?lang=arl منظمة العمل الدولية ، تقرير المرأة في قطاع الأعمال والاداره ، المكتب الإقليمي للاول العربية ، بيروت،2016.ص14

أولا: مؤشر نسبة العمالة إلى عدد السكان، إناث

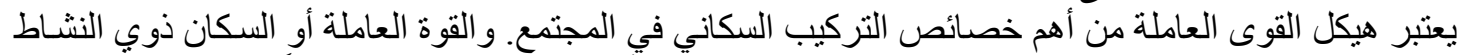

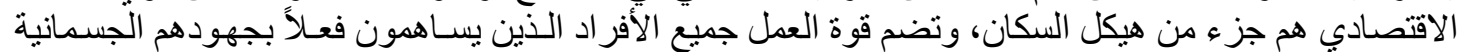

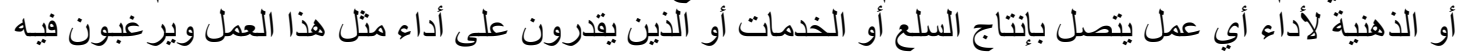
وينثون عنه.

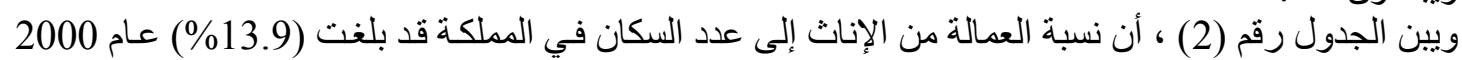

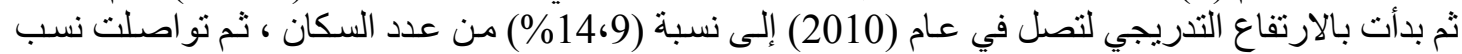

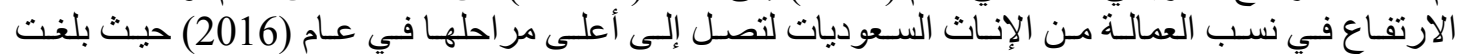
النسبة(177\%) ـ ثم انخفضت بعد ذلك بنسبة بسيطة في الأعو ام التي تلت عام

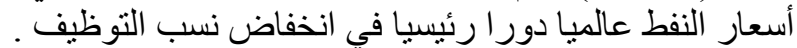




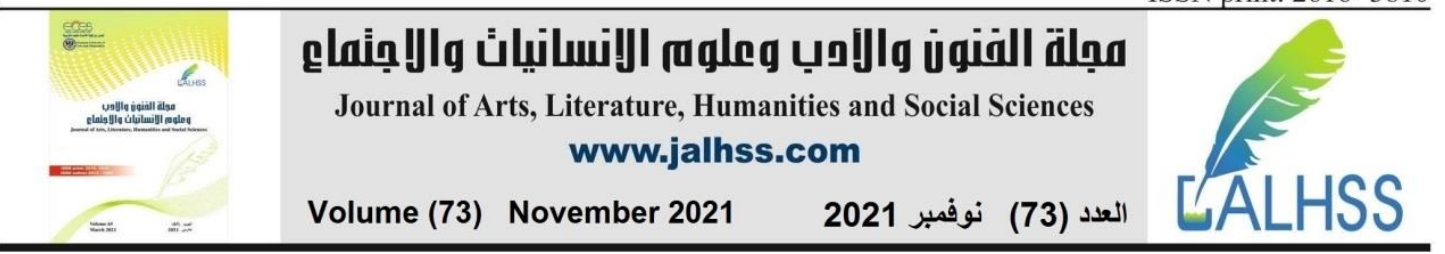

\section{ثانيا: معدل المشاركة في القوى العاملة (15 سنة وما فوق)، إناث}

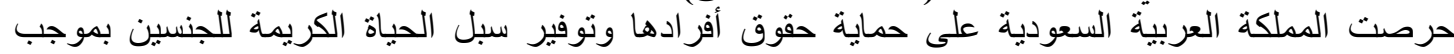

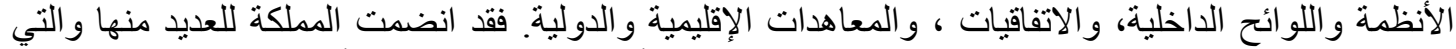

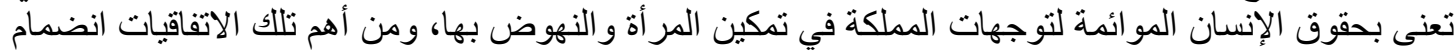

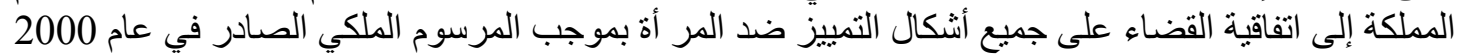

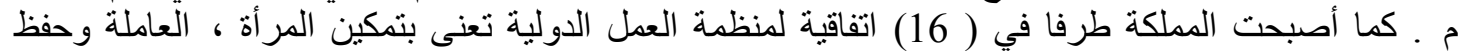

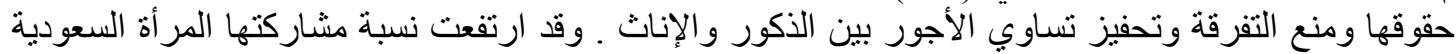

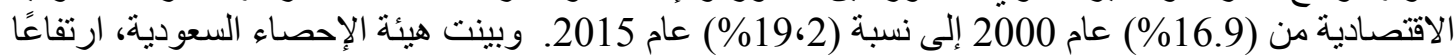

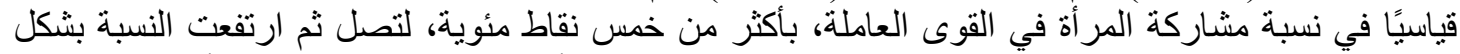

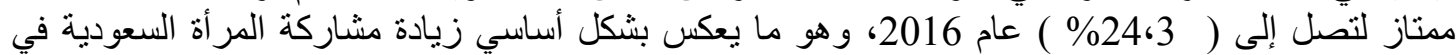

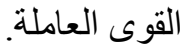

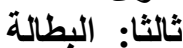

تعد البطالة ظاهرة عامة في سوق العمل العربي إلا أن وَقْعَ هذه الظاهرة أكثر حدة على النساء منهـ على الرجـال.

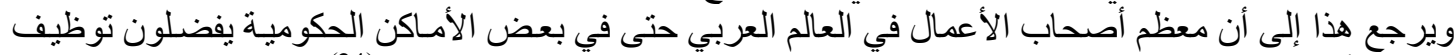

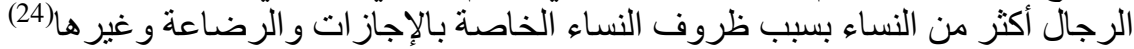

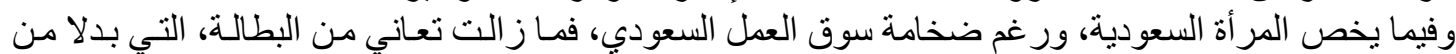

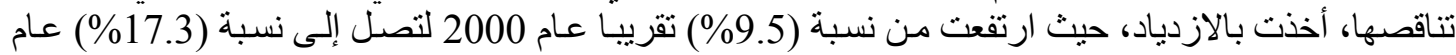

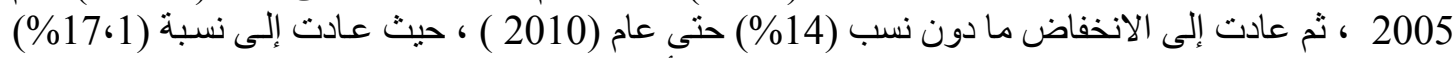

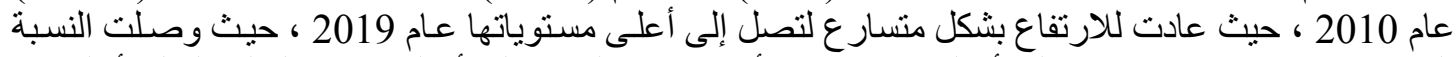

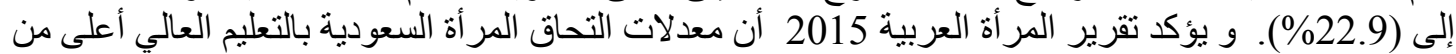

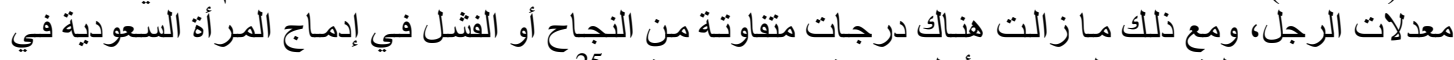

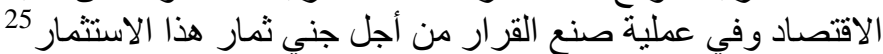

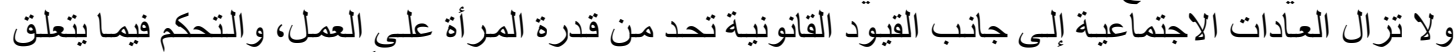

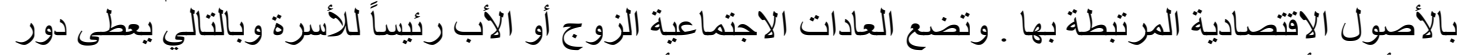

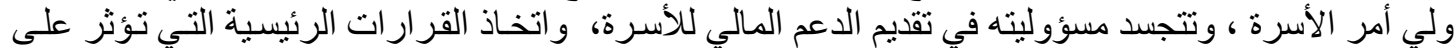

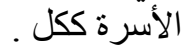

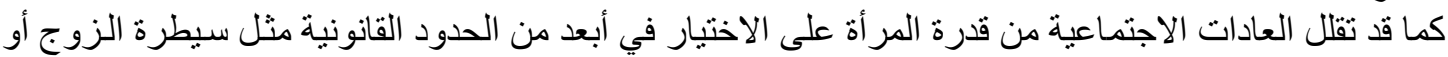

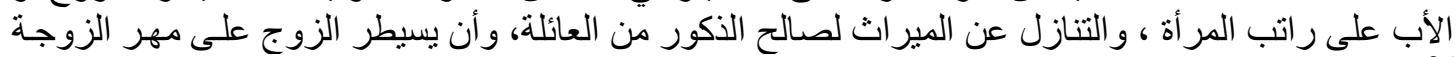

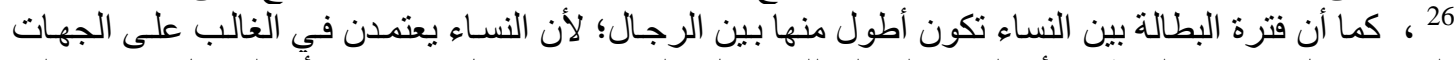

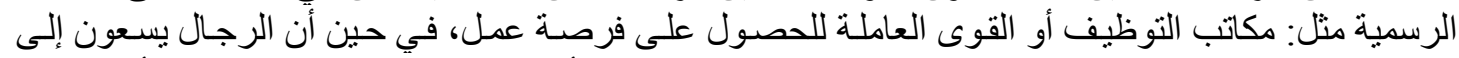

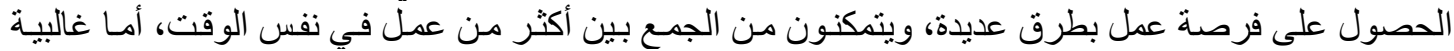
النساء فلا يعملن إلا في عمل واحد بسبب مسؤولياتهن في المنزل، ويضاف إلى مـا سبق أن بطالة المر أة العربية العية

(242حسن محمد العثمان، مشاركة المر أة الأردنية في التتمية البشرية الو اقع و المعوقات، مجلة مؤتة للبحوث و الدراسات ـ

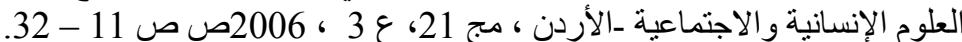

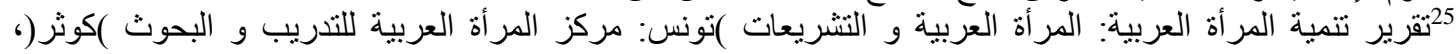
. 2015)ص 93

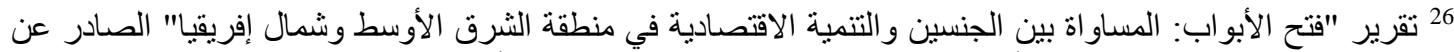

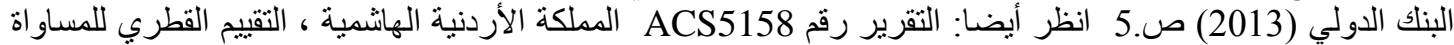

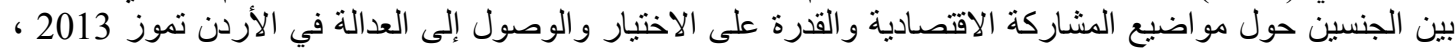
مجمو عة التنمية الاجتماعية و الاقتصادية لمنطقة الثرق الأوسط وشمال أفريقيا 


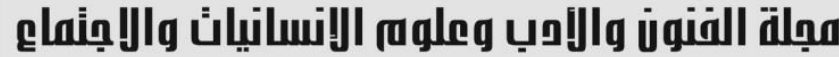

Journal of Arts, Literature, Humanities and Social Sciences www.jalhss.com

Volume (73) November 2021

العدد (73) نوفمبر 2021

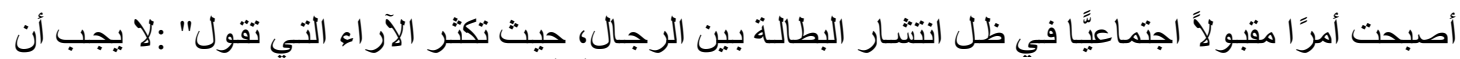

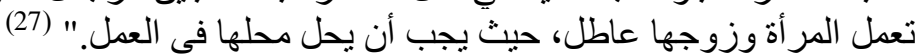

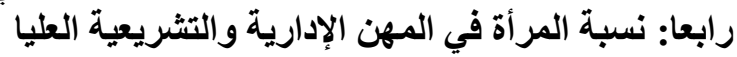

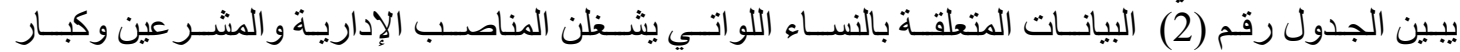

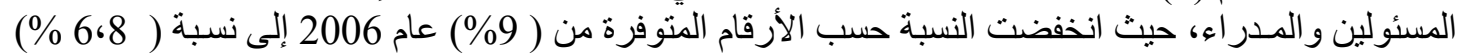

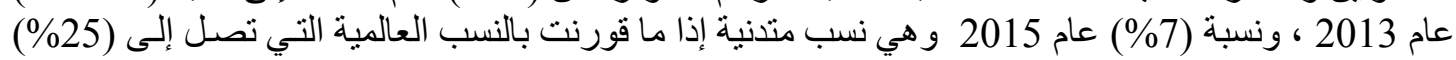

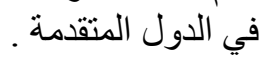

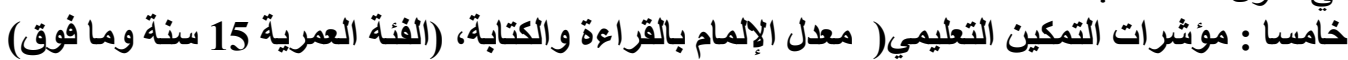

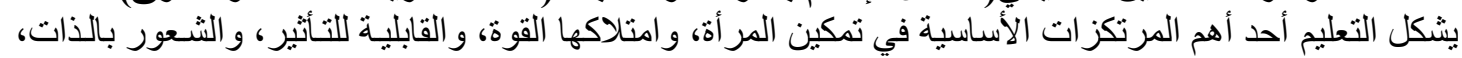

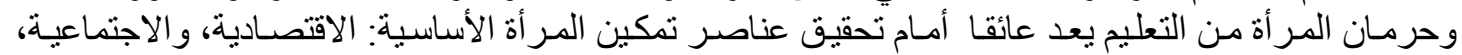

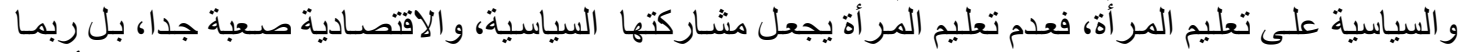

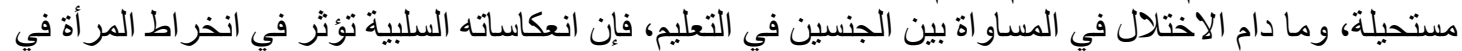

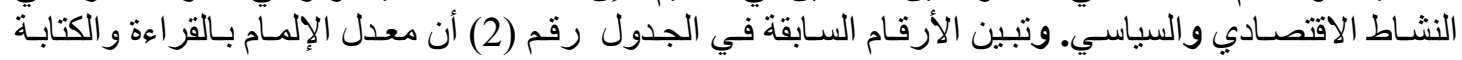

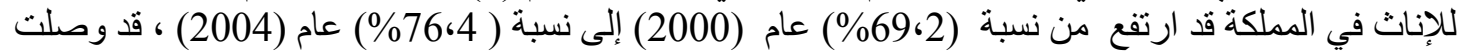

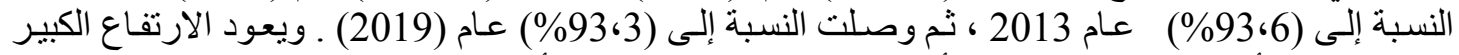

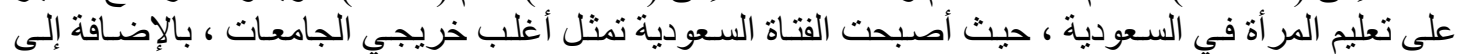

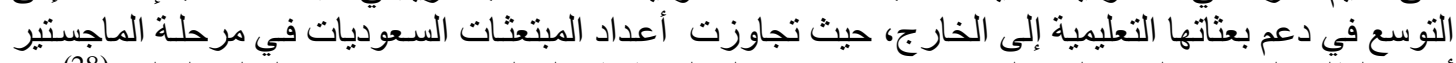

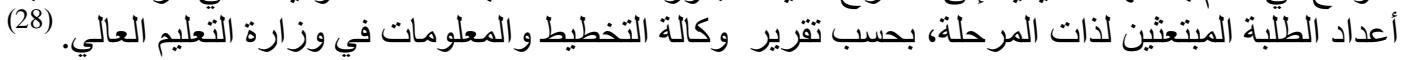

مؤشر المساواة في الأجر (الفجوة في الأجور بين الجنسين)

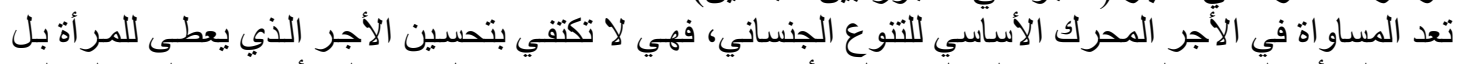

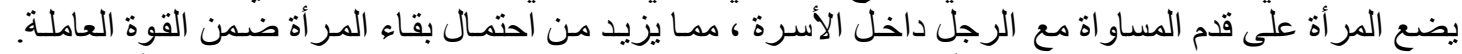

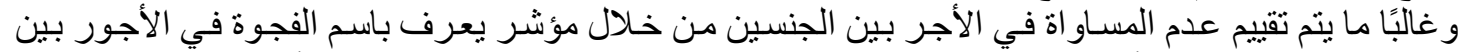

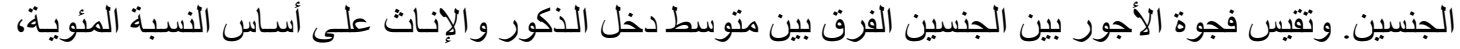

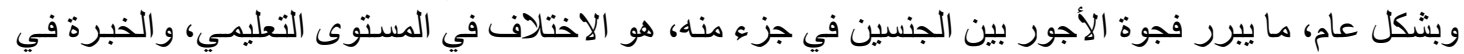

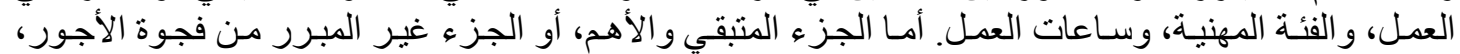

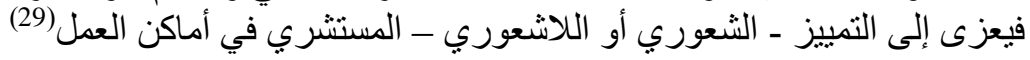

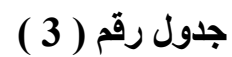

نسبة الدخل المكتسب المقر للإناث إلى دخل الذكور (\%) (\%)

\begin{tabular}{|r|r|}
\hline & \\
\hline 2000 & 17 \\
\hline 2002 & 21 \\
\hline 2006 & 22 \\
\hline 2013 & 28 \\
\hline 2014 & 28 \\
\hline
\end{tabular}

(27)مصطفى عبد الله عبد القاسم خشيم ، معوقات تمكين المر أة في البلان العربية : الواقع و الطموح، مجلة شؤون عربية

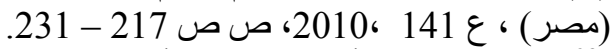
(28)تقرير تنمية المرأة العربية: المر أة العربية و التثريعات، تونس: مركز المرأة العربية للتنريب و البحوث (كوثر)، 93 صن. 2015 (29)منظمة العمل الدولية، تقرير المسـاو اة فـي الأجر المحرك الرئيسي للمساو اة بين الجنسين، 2014-2015، ص2 . 


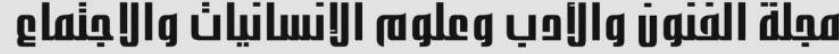

Journal of Arts, Literature, Humanities and Social Sciences www.jalhss.com

Volume (73) November 2021

العدد (73) ن نوفمبر 2021

\begin{tabular}{|r|r|}
\hline 2015 & 27 \\
\hline 2016 & 29 \\
\hline 2017 & 21.7 \\
\hline 2018 & 21.7 \\
\hline 2019 & 23.7 \\
\hline
\end{tabular}

The Global Gender Gap Report

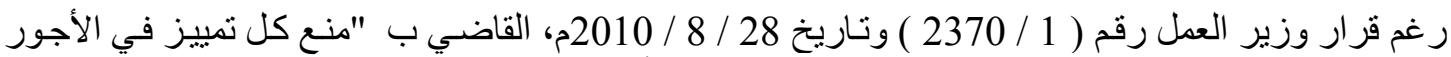

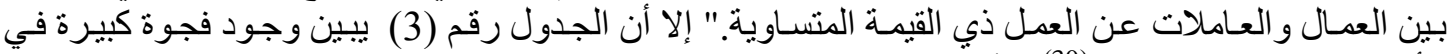

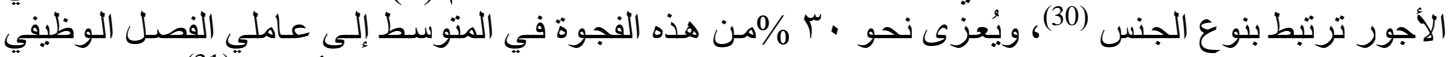

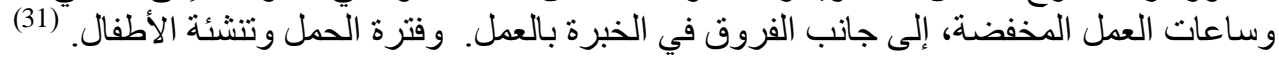

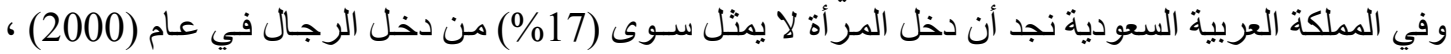

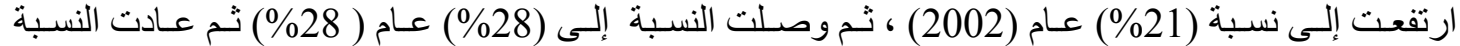

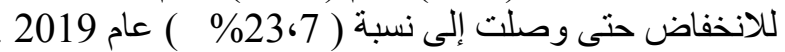

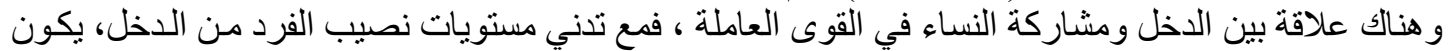

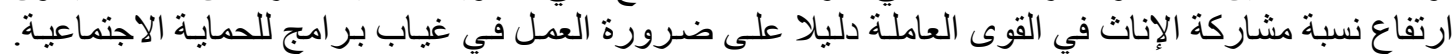

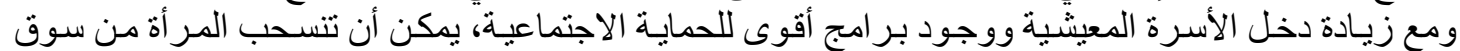

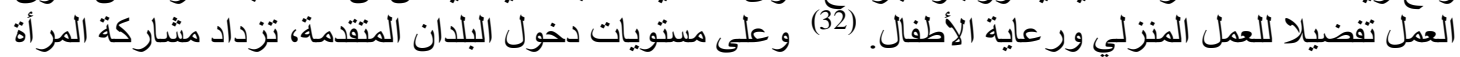

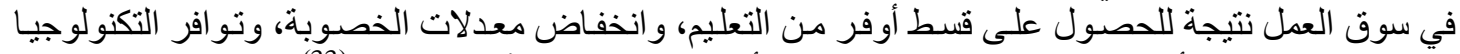

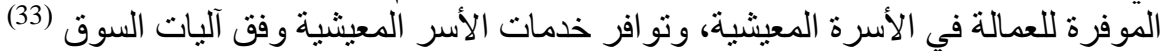

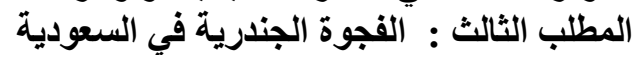

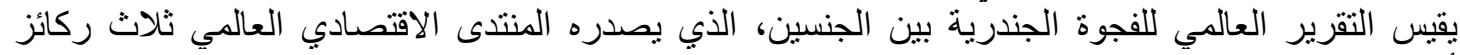

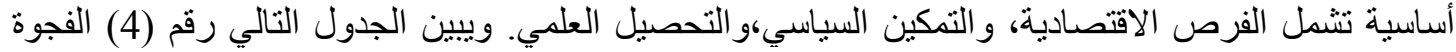
الجندرية في السعودية خلال الفترة من عام (2006-2020).

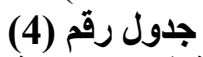

الفجوة الجندرية في السعودية( (4) (2020-2006)

\begin{tabular}{|c|c|c|c|c|c|c|c|c|}
\hline \multicolumn{3}{|c|}{ الفجوة الجندرية } & \multicolumn{2}{|c|}{ الفجوة الاقتصـادية } & \multicolumn{2}{|c|}{ الفجوة التعليمية } & \multicolumn{2}{|c|}{ الفجوة السياسية } \\
\hline السنو ات & الرتبة & القبمة & الرتبة & القيمة & الرتبة & القيمة & الرتبة & القيمة \\
\hline 2006 & 114 & 52.4 & 115 & 0.24 & 93 & 0.88 & 115 & 0.00 \\
\hline 2007 & 124 & 56.4 & 127 & 32.1 & 87 & 96.1 & 128 & 0.00 \\
\hline 2008 & 128 & 55.3 & 129 & 25.9 & 85 & 0.979 & 130 & 0.00 \\
\hline 2009 & 130 & 56.5 & 133 & 0.31 & 92 & 0.975 & 134 & 0.00 \\
\hline 2010 & 129 & 57.1 & 132 & 33.5 & 92 & 0.974 & 131 & 0.00 \\
\hline 2011 & 131 & 57.5 & 133 & 35.8 & 92 & 0.967 & 132 & 0.00 \\
\hline
\end{tabular}

(30) تقدر فجوة الأجور بين الجنسين، التي تعرَّف بأنها الفرق بين وسيط الأجور الني يتقاضاها الذكور والإناث مقسوما على وسيط الأجور التي ينقاضاها الذكور التئر

$\left({ }^{31}\right)$ World Bank, 2011, World Development Report 2012. Gender Equality and Development (Washington).

(23) رغاد لخضر وحاجي فطيمة : إثكالية الفقر في الجزائر في ظل الأهداف الإنمائية للألفية الثالثة، مجلة أبحاث

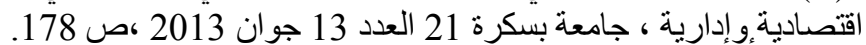

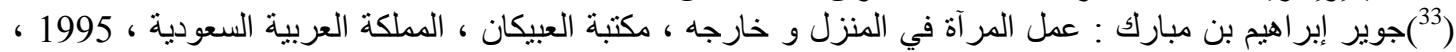




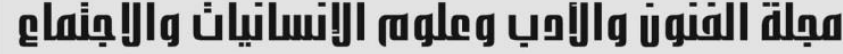

Journal of Arts, Literature, Humanities and Social Sciences www.jalhss.com

Volume (73) November 2021

العدد (73) نوفمبر 2021

ÁLHSS

\begin{tabular}{|c|c|c|c|c|c|c|c|c|}
\hline 2012 & 131 & 57.3 & 133 & 0.34 & 91 & 0.976 & 133 & 0.00 \\
\hline 2013 & 127 & 58.7 & 134 & 32.2 & 90 & 0.976 & 105 & 0.00 \\
\hline 2014 & 130 & 58.7 & 137 & 38.9 & 86 & 98.7 & 117 & 0.07 \\
\hline 2015 & 134 & 60.5 & 138 & 38.7 & 82 & 98.8 & 121 & 0.07 \\
\hline \multicolumn{2}{|c|}{ نسبة التغير (2006-2015) } & +0.08 & \multicolumn{2}{|r|}{+14.7} & \multicolumn{2}{|c|}{$10.9 \quad-$} & \multicolumn{2}{|r|}{+0.07} \\
\hline 2016 & 141 & 58.3 & 142 & 32.8 & 105 & 96.1 & 121 & 0.07 \\
\hline 2017 & 138 & 58.4 & 142 & 0.32 & 96 & 97.5 & 124 & 0.07 \\
\hline 2018 & 141 & 0.59 & 145 & 33.7 & 93 & 98.2 & 127 & 0.07 \\
\hline 2019 & 146 & 59.9 & 148 & 37.5 & 91 & 98.3 & 136 & 0.07 \\
\hline \multicolumn{2}{|c|}{ نسبة التغير (2016-2020) } & +1.9 & & $4.3 \%$ & \multicolumn{2}{|r|}{$\% 2 \cdot 2$} & \multicolumn{2}{|r|}{0.000} \\
\hline
\end{tabular}

https://www.weforum.org/reports/gender-gap-2020-report-100-The Global Gender Gap Report years-pay-equality

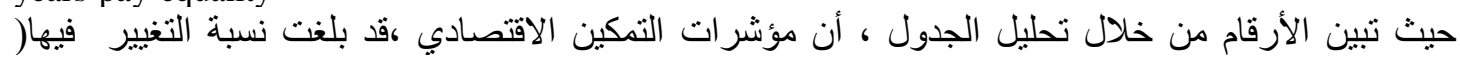

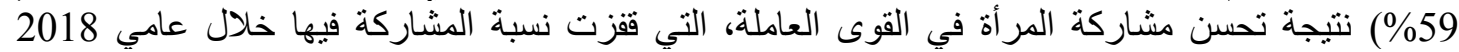

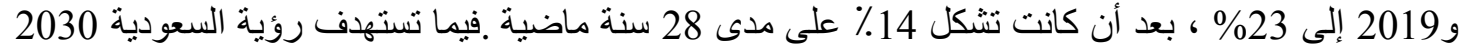
رفع النسبة إلى 30٪. حيث تم السماح للمر أة السعودية عام (2018) بالبدء بعملها التجاري والاستفادة من التهات الخدمات الحكومية دون الحاجة لمو افقة ولي الأمر ، وتعيين أول امر أة في منصب أمان أمين مجلس منطقة سعودية في

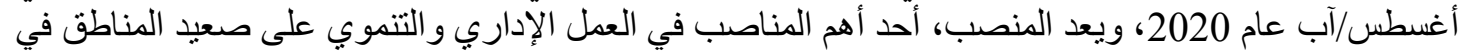

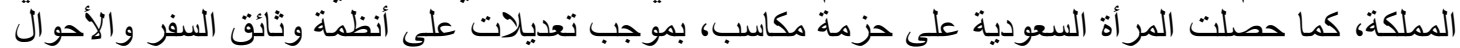
المدنية و العمل، جرت في 2 أغسطس/آب 2019، منحت المر أة المزيد من الحقوق على أكثر من صعيد، و أتاحت

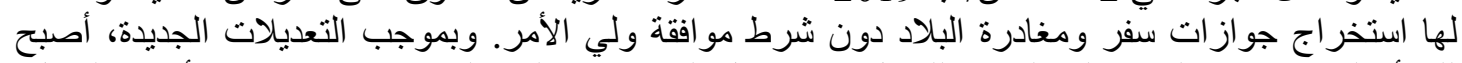

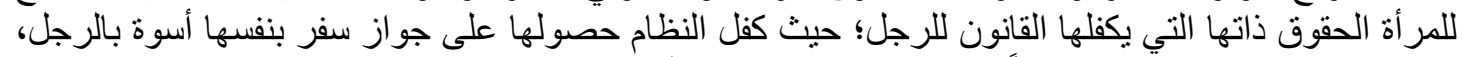

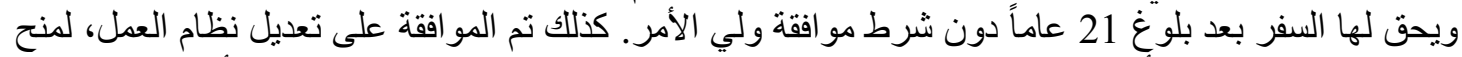
المزيد من الحقوق للمر أة ووضعها على قدم المساواة مع الرجل. وعلى وعلى صعيد المساواة في الأجور و التحصيل

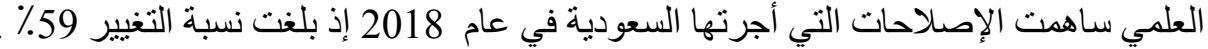

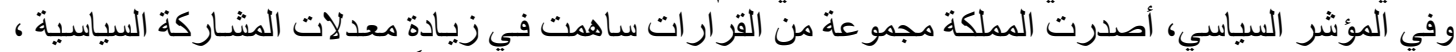

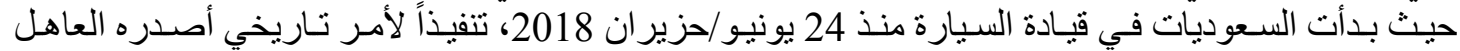

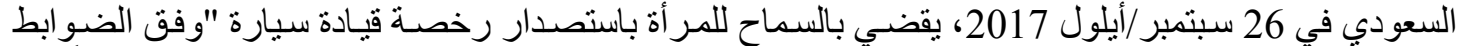

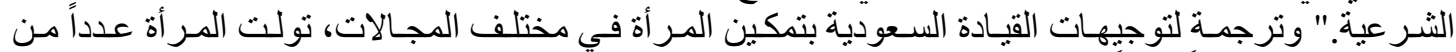
الوظائف كانت حكر اً سابقاً على الرجال في القطاعين الحكومي والخاص. وفي وفي هذا الصدد، تم تعبين الأميرة ريما

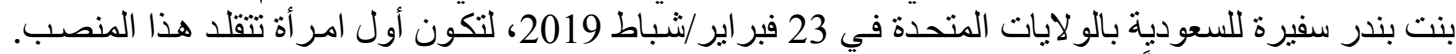

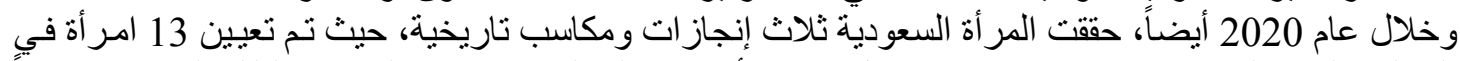

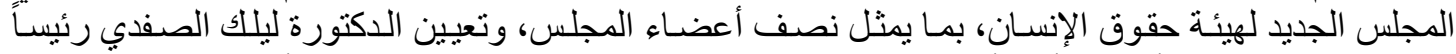

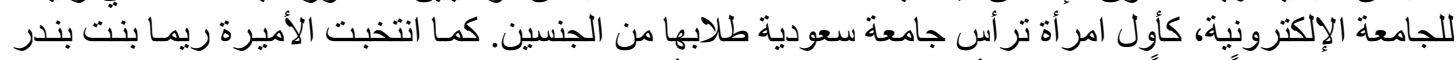

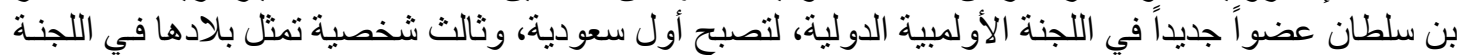
الأولمبية الدولية. وفي يناير/كانون الثاني الماضي، تم تعيين الأمبرة هيفاء بنت عبد العزيز آل مقرن مندوبة دائمة

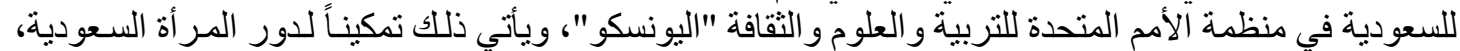

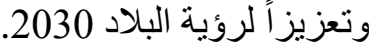

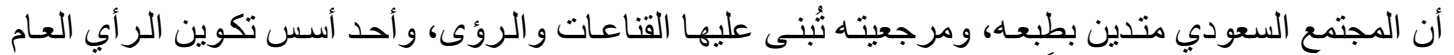

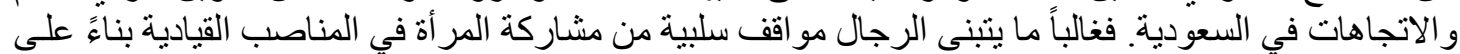

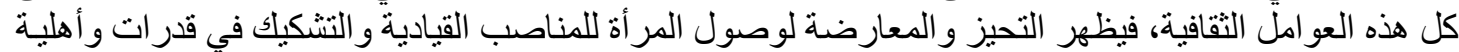

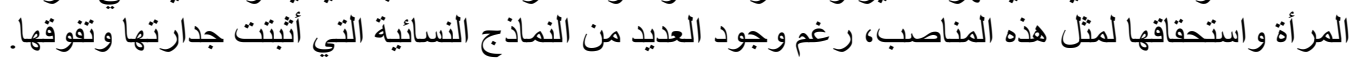




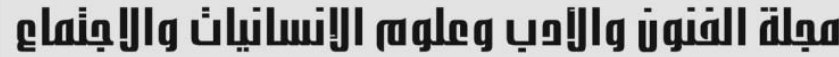

Journal of Arts, Literature, Humanities and Social Sciences www.jalhss.com

شكل موضوع تمكين المر أة وزيادة مشاركتها الاقتصادية واحدة من أهداف رؤية (2030 ) التي تنص على منى منح

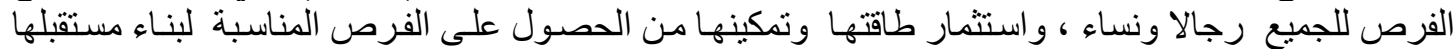

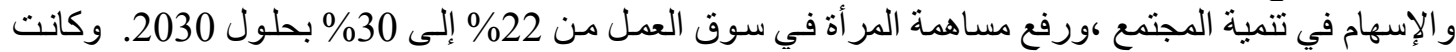

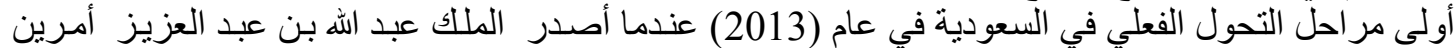

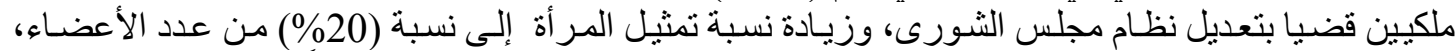

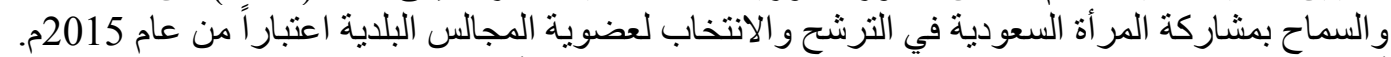

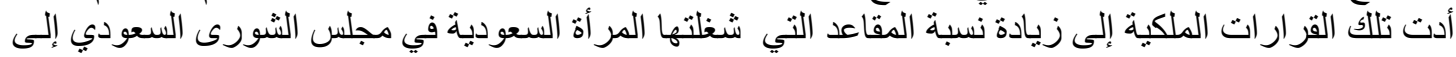

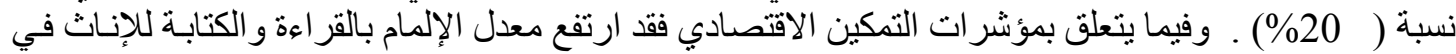

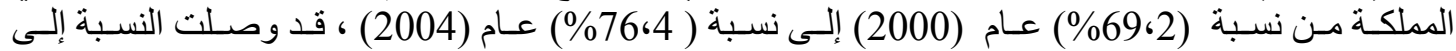

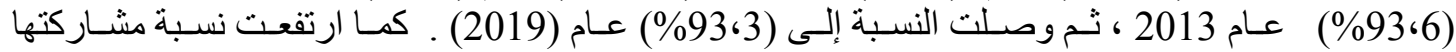

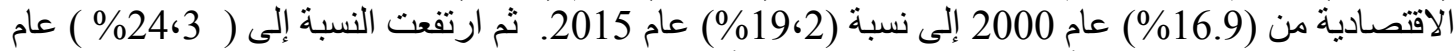

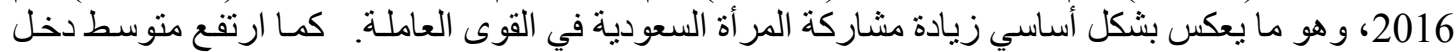

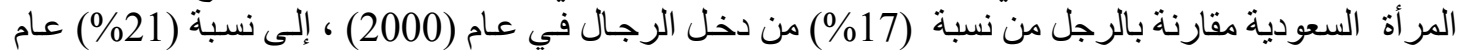

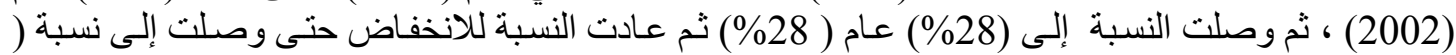

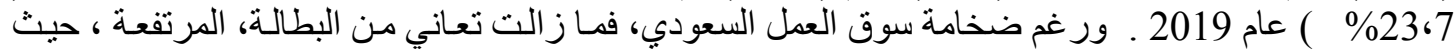

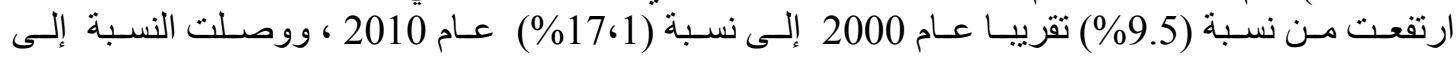
. 2019 (\%22.9)

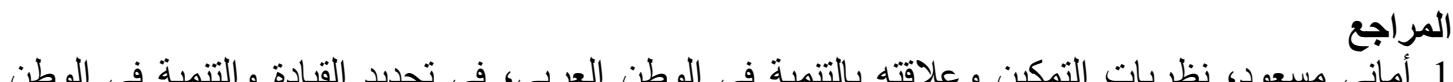

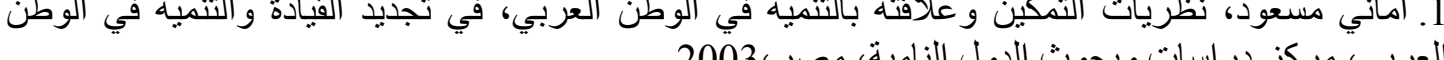

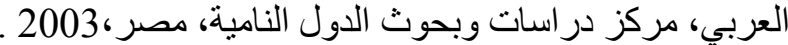
2. أوراق كارنيجي، المتاهة السعودية: تقويم الانفتاح السياسي الحالي،سلسلة الثرق الأوسط،رقم 66، ابريل-

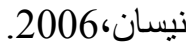
3. البنك الدولي،النوع الاجتماعي و التتمية في الثرق الأوسط وشمال أفريقيا،نظمة الأمم المتحدة، 2003.

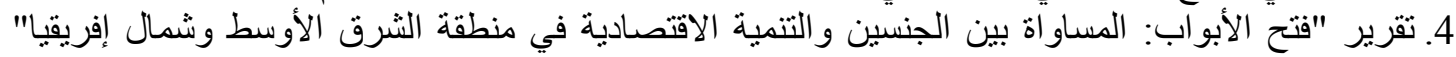

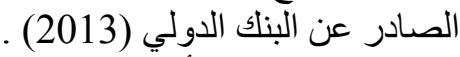
5. تقرير تتميـة المر أة التعربيـة: المر أة العربيـة و التشريعات )تونس: مركز المر أة العربيـة للتدريب و البحوث

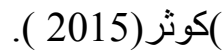

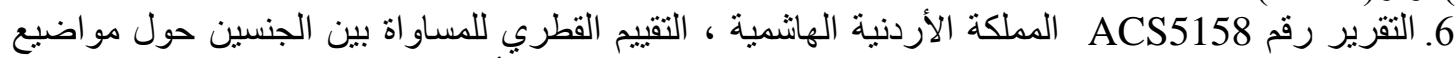

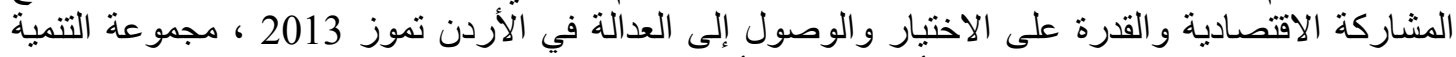

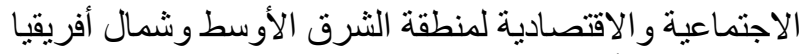

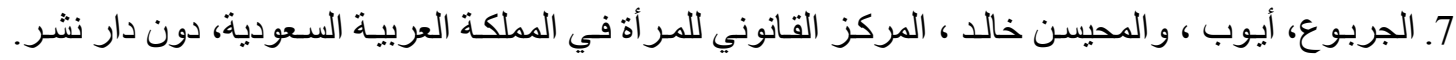

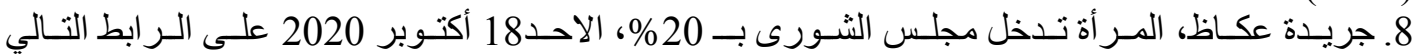
https://www.okaz.com.sa/news/local/2045145 9. جوير إبر اهيم بن مبارك : عمل المر آة في المنزل و خارجهـ ، مكتبـة العبيكان ، المملكة العربيـة السعودية ، 1995

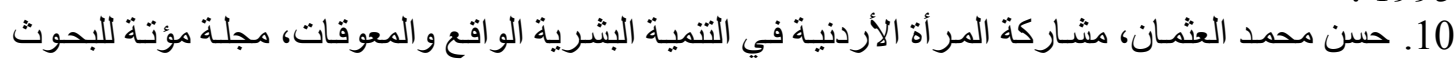

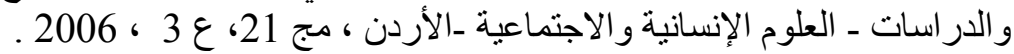

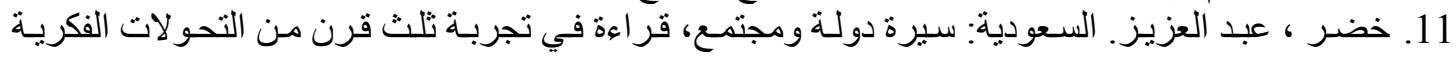




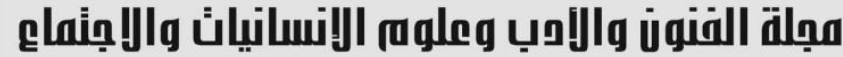

Journal of Arts, Literature, Humanities and Social Sciences www.jalhss.com

Volume (73) November 2021

العدد (73) نوفمبر 2021

12. رغاد لخضـر وحاجي فطيمة : إثكالية الفقر في الجزائر في ظل الأهداف الإنمائيـة للألفيـة الثالثة، مجلـة

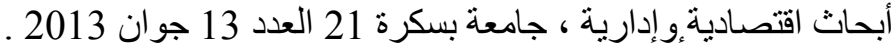

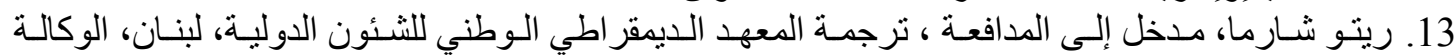
الأمريكية للتنمية الدولية، مكتب شمال ملال أفريقيا، 2002.

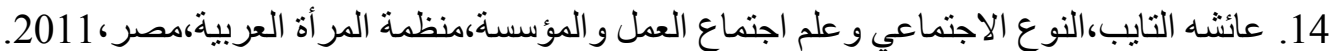

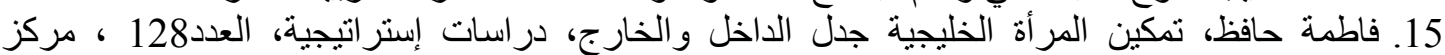

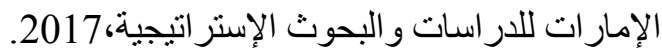

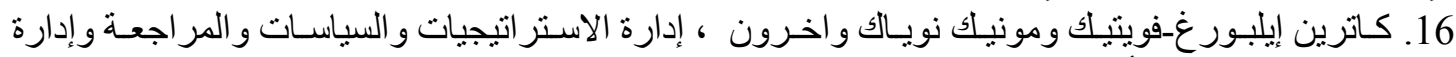

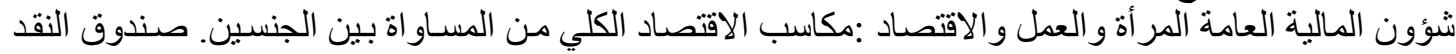

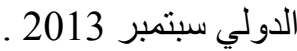
17. محمد أبي بكر الرازي الرئ 1997)مختار الصحاح، بيروت: المكتبة العصرية، ص297 معجم اللغة العربيـة :

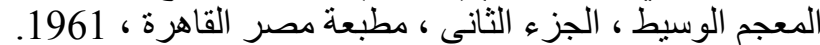

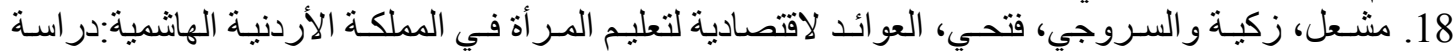

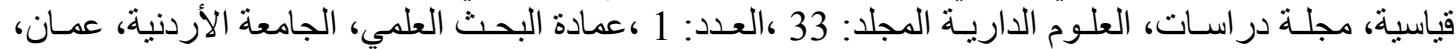

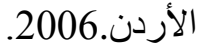

19. مصطفى عبد الله عبد القاسم خشيم ، معوقات تمكين المر أة في البلدان العربية : الو اقع و الطموح، مجلة

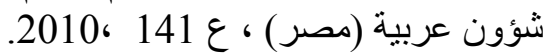

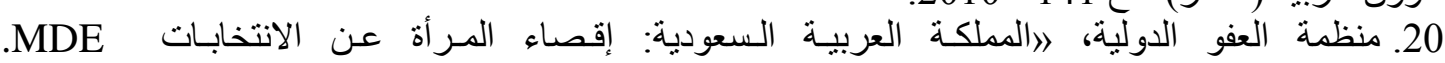

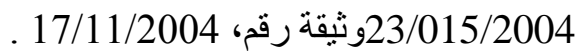

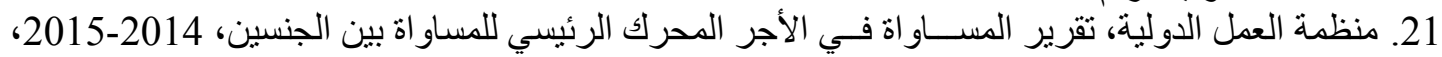

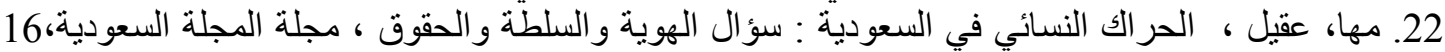

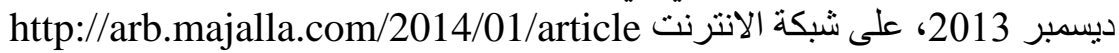

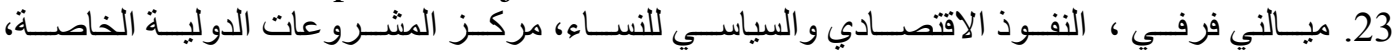
http://www.cipearabia.org/files/pdf/Feature_Service/Political_And\%20Economic_Power_of_Women.

pd 24. نورة عبد الرحمن ، تمكين المر أة السعودية، 2009 / / 1430 هـ ـ.

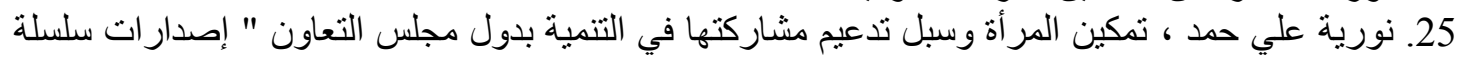

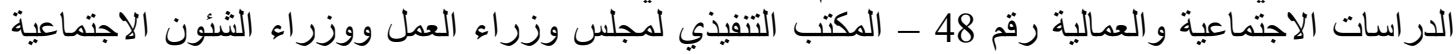

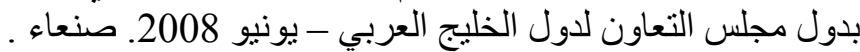

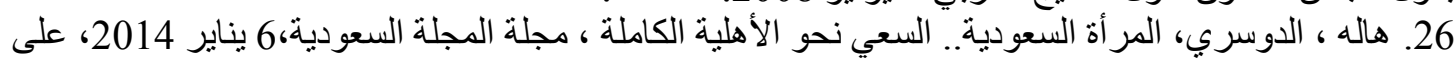

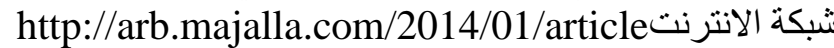

27. Barara Rowland- Sedar, Peregrine Scwartz-shea, "Empowering Women: Self Autonomy and Responsibility", The Western Political Quarterly, Vol. 44, No.3, Sep., 1991.

28. The United Nations Fourth World Conference on Women: Platform for Action, (China:1995): (http://www.un.org/womenwatch/daw/beijing/platform/decision.htm)

29. Gita Sen and Batilwala Sirilatha, "Empowering Women for Reproductive Rights", Women's Empowerment and Demographic Process, Moving Beyond Cairo, New York: Oxford University Press, 2000,

30. World Bank, 2011, World Development Report 2012. Gender Equality and Development (Washington). 